\title{
Heterogeneity in Proline Hydroxylation of Fibrillar Collagens Observed by Mass Spectrometry
}

Michele Kirchner ${ }^{1,2}$, Haiteng Deng ${ }^{3 \# a}$ and Yujia $\mathrm{Xu}^{1,2 *}$

${ }^{1}$ Department of Chemistry, Hunter College of CUNY, 695 Park Ave, New York, NY 10065;

2 The Graduate Center CUNY, The City University of New York, $3655^{\text {th }}$ Ave., New York, NY, 20016

${ }^{3}$ Proteomics Resource Center, The Rockefeller University, 1230 York Ave., New York, NY 10065;

\#a Current Address: School of Life Sciences, Tsinghua University, Haidian District, China (100084)

* Corresponding author

E-mail: yujia.xu@hunter.cuny.edu 


\section{Abstract}

2 Collagen is the major protein in the extracellular matrix and plays vital roles in tissue

3 development and function. Collagen is also one of the most processed proteins in its biosynthesis.

4 The most prominent post-translational modification (PTM) of collagen is the hydroxylation of

5 Pro residues in the Y-position of the characteristic (Gly-Xaa-Yaa) repeating amino acid sequence

6 of a collagen triple helix. Recent studies using mass-spectrometry (MS) and tandem MS

7 sequencing (MS/MS) have revealed unexpected hydroxylation of Pro residues in the X-positions

8 (X-Hyp). The newly identified X-Hyp residues appear to be highly heterogeneous in location and

9 percent occupancy. In order to understand the dynamic nature of the new X-Hyps and their

10 potential impact on applications of MS and MS/MS for collagen research, we sampled four

11 different collagen samples using standard MS and MS/MS techniques. We found considerable

12 variations in the degree of PTMs of the same collagen from different organisms and/or tissues.

13 The rat tail tendon type I collagen is particularly variable in terms of both over-hydroxylation of

14 Pro in the X-position and under-hydroxylation of Pro in the Y-position. In contrast, only a few

15 unexpected PTMs in collagens type I and type III from human placenta were observed. The

16 reproducibility of the different sequencing efforts of the same sample is also limited especially

17 when the modified species are present at a low population, presumably due to the unpredictable

18 nature of the ionization process. Additionally, despite the heterogeneous preparation and

19 sourcing, collagen samples from commercial sources do not show elevated variations in PTMs

20 compared to samples prepared from a single tissue and/or organism. These findings will

21 contribute to the growing body of information regarding the PTMs of collagen by MS

22 technology, and culminate to a more comprehensive understanding of the extent and the

23 functional roles of the PTMs of collagen. 


\section{Abbreviations page:}

28 Both the single letter and the three letter abbreviations of an amino acid will be used with the 29 following additions: Hyp or O stands for 4R-hydroxylated proline and 3Hyp stands for 3-

30 hydroxylated proline. When needed for clarity, the lower case single letter abbreviation will be 31 used to represent the genomic DNA sequence, and upper case ones the sequence seen in the 32 peptides. 


\section{Introduction}

The new technologies in mass spectrometry (MS) have transformed collagen research in

37 recent years, and even expanded the field of collagen research to include archeology for the

38 study of ancient species $(1,2)$. The high sensitivity of MS and tandem MS sequencing (MS/MS)

39 also led to the identification of new post-translational modifications (PTMs) in fibrillar collagen

40 (3-10). Fibrillar collagen is the major protein of bone, skin, cartilage, and blood vessel walls, and

41 plays critical roles in many physiological and pathological events $(11,12)$. The newly discovered

42 PTMs that are of particular interest is the 3-hydroxyproline residues (3Hyp, or 3O) in unexpected

43 locations, since mutations in the enzymes involved in the formation of 3Hyp have been linked to

44 severe cases of Osteogenesis Imperfecta (the brittle bone diseases) $(13,14)$. Yet, emerging from

45 further studies of 3Нyp is an increasingly more heterogeneous pattern in terms of number,

46 location, and the percent occupancy of this PTM $(4,10)$. Such varied patterns of 3Hyp make it

47 challenging to pin down the specific molecular interactions involving 3Hyp. At the same time,

48 collagens have been used as biomarkers for disease detection, species identification, and

49 investigations of the involvement of collagen in cancer metastasis, tissue remodeling, the

50 homeostasis of extracellular matrix and cell signaling, and the mineralization process of bones,

51 to name just a few (15-18). The unpredictable nature of prolyl-3-hydroxylation has hampered the

52 application of MS in these and other related research that rely on a precise knowledge of the

53 genomic sequence and the PTMs of specific segments of collagen. Both the functional research

54 of PTMs and the applications of MS for a broad range of quantitative studies of collagen depend

55 on a comprehensive understanding of the extent and the variations of PTMs.

57 of collagen (often referred to as the $\alpha$ chains) usually comprise a triple helix domain together 
with propeptides at both the $\mathrm{N}$ - and C-termini. The triple helix domain of fibrillar collagens, which include collagens type I-III, V and XI, often contains more than 1000 amino acid residues in the uninterrupted (Gly-Xaa-Yaa) repeating amino acid sequence; while the Xaa and Yaa can be any amino acid. Collagen is known for its exceedingly high content of Pro: about $10-12 \%$ of the residues at each of the $\mathrm{X}$ - and $\mathrm{Y}$-positions are Pro(19). In addition to the processing of the Nand C-propeptides, the residues of the triple helix domain are also heavily hydroxylated and glycosylated during the post-translational modification $(20,21)$. The major PTM of collagen is the prolyl-4-hydroxylation of Pro residues in the Y-position of the (Gly-Xaa-Yaa) triad (11). This is a stable, invariant modification; nearly all Pro residues in the Y-position are hydroxylated to 4R-hydroxyproline (4Hyp). Some Lys residues in the Y-position are also hydrolyzed to hydroxylysine (Hyl), which are often glycosylated and/or form covalent cross-links through an oxidation process catalyzed by lysyl oxidase during tissue maturation $(22,23)$. Until recently, only one Pro residue in the X-position, Pro $^{986}$ of the $\alpha 1$ chain of type I and type II collagen (the $\alpha 1$ (I) chain and the $\alpha 1$ (II) chain, respectively) was known to be a 3R-hydroxyproline (3Hyp), in which the hydroxyl group is appended on the $\beta$-carbon (the 3-position) of the pyrrole ring of the

73 Pro instead of on the $\gamma$-carbon (the 4-position) of the pyrrole ring as in the case of 4Hyp (24). A

74 more recent study using MS and MS/MS found several other Pro in the X-position of fibrillar 75 collagens were also hydroxylated, including Pro ${ }^{707}$ of $\alpha 2(\mathrm{I})$ chain, Pro ${ }^{944}$ of $\alpha 1$ (II) and $\alpha 2(\mathrm{~V})$ 76 chains, and Pro $^{470}$ of $\alpha 2(\mathrm{~V})$ chain $(9,10)$. Some of the X-Hyps were later confirmed to be a

77 3Hyp by Edman sequencing. Multiple 3Hyps were also found in the repeating genomic sequence

78 of gly-pro-pro (gpp) at the C-terminal end of the $\alpha 1(\mathrm{I})$ and $\alpha 2(\mathrm{I})$ chains, although their exact

79 locations could not be specified (6). Differing from the $3 \mathrm{Hyp}^{986}$, which is invariant and has a 80 nearly 100\% occupancy, the newly discovered X-Hyp and 3Hyp residues are often found in a 
81 mixed population having the percentage of hydroxylated moiety ranging from $10 \%$ to $80 \%$

82 depending on the location, the type of collagen, the tissue, and the organism $(4,6,9,10)$.

The PTMs of collagen are considered to be essential for its secretion and self-assembly,

84 and the immune responses of tissues (10, 20, 25-29), although much of the molecular

85 mechanisms of their involvements remain unclear. Impaired prolyl-4-hydroxylation is the major

86 cause of the condition of scurvy linked to the fragility in skin, blood vessels, and dentine (20). In

87 this case, the tissue fragility was linked to the decreased stability of the collagen triple helix due

88 to the lack of 4Hyp. Studies using triple helical peptides have firmly established the significant

89 stabilizing effects of a 4Hyp in the Y-position compared to that of a Pro (30-33). Organisms

90 having a higher physiological temperature often have a higher content of 4Hyp (34). The Hyl

91 related glycosylation and cross-links were also considered an important part of the fibril stability,

92 and the extent of the modification increases with the advance of the developmental stages(35-37).

93 The understanding of the function of 3Hyp is more limited, except it is important for bone health

$94(13,38,39)$.

Determining the biological functions of PTMs in fibrillar collagen is often confounded by

96 the complex structural hierarchy of collagen fibrils $(11,12)$. The processed $\alpha$ chains of fibrillar

97 collagen frequently have over 1000 amino acid residues. Three such $\alpha$ chains, they can be

98 identical or different, come together in parallel to form the rod-shaped collagen triple helix, each

99 about $300 \mathrm{~nm}$ in length. The Gly residues at every third position are packed at the center of the

100 helix, while the side chains of the $\mathrm{X}$ and $\mathrm{Y}$ residues are largely exposed to solvent. The triple

101 helix, however, is not the functional unit of collagen. The triple helices further self-associate

102 laterally in a specific manner to form collagen fibrils having a unique $67 \mathrm{~nm}$ axially repeating

103 structure known as the $D$-period. Any modifications of residues in X or Y positions can 
104 potentially impact the stability of the triple helix, the molecular recognition process during

105 fibrillogenesis, and the interactions of collagen fibrils with cell receptors and other

106 macromolecules during tissue development and function. Eyre and colleagues postulate the

107 newly discovered 3Hyps are involved in fibrillogenesis because the locations of some of them

108 are approximately a $D$-period apart $(6,8)$. However, considering the low occupancy at some of

109 the locations, it remains to be evaluated at what extent of the hydroxylation the purported

110 interactions involving 3Hyp will have a sustained impact on the fibril assembly. A systematic

111 MS/MS characterization of rat type I collagen found an increased occupancy of 3Hyp with the

112 developmental stages in rat-tail tendon, but the same study also reported a relatively constant

113 extent of hydroxylation of type I collagen in bones and in skin (4). If the prevalent presence of

114 4Hyp is consistent with its structural role on the overall stability of the triple helix and the

115 collagen fibrils, the highly diverged and sporadic presence of 3Hyp may suggest a more dynamic

116 role for this unique collagen PTM, which may involve the hydroxylation of specific X-Pro

117 residues at specific stages of development and/or in response to specific cues of the extracellular

118 matrix. Similar dynamic PTMs were reported to be part of the 'epigenetic code' of histone and

119 other proteins (40). Under such a dynamic regulation, 3Hyps are likely to present in low quantity:

120 a few selected X-positions (comparing to more than 100 4Hyp residues in the Y-positions) in

121 each $\alpha$ chain, and only in a subpopulation of the $\alpha$ chain. Both the locations of 3 Hyp and the

122 occupancy at a specific location may also vary depending on the physiological conditions of the

123 tissues. Deciphering such dynamic patterns of 3-hydroxylation would require both robust

124 protocols of quantitative detection and extensive sampling of collagens from different sources.

126 regulation from the statistical nature of the techniques used for detection and/or for sample 
127 handling. MS and MS/MS are the technique of choice for studying PTMs of a protein, yet

128 quantitative analysis of protein samples is often complicated $(41,42)$. The situation is

129 particularly challenging for collagen due to the repetitive sequences and the high content of Pro

130 residues. Fragmentation of Pro containing peptides is often inefficient due to the well

131 characterized 'proline effect' in MS/MS which predicts a biased, sequence dependent potential to

132 fragment N-terminal to a Pro bond during collision induced dissociation (CID) (3, 10, 43-45). In

133 the case of the detection of 3Hyp the high frequency of the genomic sequence of pro-gly-pro-pro

134 moiety further complicated the precise localization of the hydroxyl group without a good series

135 of fragmented ions. Aside from functional dynamics, there is often an innate level of variations

136 in the PTMs of a protein between individuals and between different organisms. Without a known

137 priori on the statistical distribution of the PTMs in a specific tissue at a specific developmental

138 stage, even a carefully designed study can only reflect a statistical snapshot. Collagens produced

139 by recombinant systems may appear to be a well-controlled source of more homogeneous

140 collagens. However, the expression of a foreign gene(s) can skew the PTM processes in a host

141 cell leading to a different PTM pattern (2).

To gain a better understanding of the average impact of the prolyl-hydroxylation in both

143 the $\mathrm{X}$ and the $\mathrm{Y}$ positions and the reliability of the detection by standard MS techniques, we

144 carried out MS/MS sequencing of several samples of collagen from commercial sources and of

145 collagen isolated from tissues. Our study revealed a more varied nature of the hydroxylation of

146 proline residues in the type I collagen and substantial differences in the hydroxylation pattern

147 among different collagens. The commercial collagens are often scorned as being impure because

148 their productions often rely on batch collection of samples from mixed sources. However, this

149 'mixed' nature of commercial collagens can be a good statistical representation of the overall 
extent of different PTMs. Additionally, commercial collagens are very frequently used as

151 standards for analytical analyses, and as extracellular matrix substitutes in various biological and

152 biomedical studies that rely on specific interactions with residues on collagen including the

153 PTMs. A better understanding of the PTMs of commercial collagen samples will enhance the

154 sensitivity and reliability of these research efforts. Mapping out all the 3Hyp residues with the

155 highest sensitivity and accuracy is not the main focus of this work. Rather, we seek to understand

156 the reliability and reproducibility of the detection of unexpected hydroxylations using the

157 standard MS approach. Furthermore, the uncertainties of PTMs on the X position complicate the

158 fundamental premises of MS studies of collagen that assumes Pro in X-positions are unmodified,

159 while those in the Y-position will inevitably have a mass increase of 16 due to the addition of the

160 hydroxyl group. The finding of this work will, thus, contribute to both the understanding of the

161 dynamics of 3Hyp and the applications of MS in other areas of collagen research.

163 Materials and Methods

166 purified from placenta, and rat collagen type I from tail tendon. The purchased collagens were

167 solubilized in $20 \mathrm{mM}$ acetic acid, $\mathrm{pH} 3$, at $4{ }^{\circ} \mathrm{C}$ and $2.4 \mathrm{mg} / \mathrm{mL}$. Fresh rat collagen type I was

168 prepared from a single rat tail tendon following a procedure published by Dr. Sergey Leikin's

169 group, and the precipitated collagen was solubilized in $20 \mathrm{mM}$ acetic acid, $\mathrm{pH} 3$, at $4{ }^{\circ} \mathrm{C}$ and 3.0

$170 \mathrm{mg} / \mathrm{mL}$ (46). Collagen was mixed with 5X SDS sample loading buffer containing $60 \mathrm{mM}$ Tris-

$171 \mathrm{HCl} \mathrm{pH} \mathrm{6.8,} \mathrm{25 \%} \mathrm{glycerol,} \mathrm{2 \%} \mathrm{SDS,} 350 \mathrm{mM}$ DTT, and 0.1\% bromophenol blue, and was run on 
172 a 4-20\% Precise gel or a 7.5\% SDS PAGE gel and stained with coomassie blue. Bands of alpha

173 chains were excised from the gels and submitted to The Rockefeller University for in-gel

174 digestion and mass spectrometry analysis.

In-gel Trypsin Digestion - The gel bands were reduced with dithiothreitol for 45 minutes at $55^{\circ} \mathrm{C}$, and alkylated with iodoacetamide for 30 minutes at room temperature in the dark. 10 $\mu \mathrm{L}$ of $0.02 \mu \mathrm{g} / \mu \mathrm{L}$ trypsin in $50 \mathrm{mM} \mathrm{NH}_{4} \mathrm{HCO}_{3} / 0.1 \%$ octyl glucopyranoside (OGP)/ $5 \mathrm{mM}$ 178 calcium chloride was used to digest each sample overnight at $37^{\circ} \mathrm{C}$ in $50 \mathrm{mM} \mathrm{NH}_{4} \mathrm{HCO}_{3}$. The 179 digestion was stopped with the addition of $5 \mu \mathrm{L}$ of $10 \%$ acetic acid, and the peptides were 180 extracted first with 30\% ACN/5\% TFA and then with 50\% ACN/5\% TFA. The samples were 181 dried down in a Speed Vac to a few microliters. Trypsin In-Solution Digestion - The collagen solution was heat denatured and digested 183 overnight with trypsin in $25 \mathrm{mM}$ ammonium bicarbonate at $37^{\circ} \mathrm{C}$. The reaction was terminated 184 by bringing the solution to a final concentration of $0.1 \%$ trifluoroacetic acid MALDI-TOF MS Analysis - Matrix, $\alpha$-cyano-4-hydroxycinnamic acid, was prepared as a

186 saturated solution in $50 \%$ acetonitrile $/ 0.1 \%$ trifluoroacetic acid. Solution digests of collagen 187 were spotted 1:1 with matrix onto a sample plate and allowed to dry. All spectra were acquired 188 using a Voyager-DE STR mass spectrometer (PE Biosystems, Foster City, CA) equipped with a 189 pulse nitrogen laser ( $\lambda=337 \mathrm{~nm}, 3 \mathrm{~Hz}$ frequency) in the reflectron positive ion, delayed

190 extraction mode. Spectra from 100 individual laser shots were averaged. LC-MS/MS Analysis - The in-gel digests and solution digest samples were

192 chromatographed using a $\mathrm{C}_{18}$ column on a Dionex HPLC eluded with a gradient of $0.1 \%$ formic 
193 acid and $100 \% \mathrm{ACN}$ and introduced into a mass spectrometer. The sequencing was done at The

194 Rockefeller University Proteomics Center.

195 Data Base Search and Analysis - For peptide identification a Mascot (Matrix Science)

196 search was performed. The .raw data files were converted to .dta or .mgf files which were then

197 used to perform a search. The database User 0710 (in house database at Rockefeller Proteomic

198 Center) containing human collagen type I and type III, and rat collagen type I, was used with

199 oxidized methionine, proline and lysine as variable modifications. The Swiss Prot database was

200 used for protein identification confirmation. For the freshly prepared rat tail, a summary report

201 file was created using Discoverer version: 1.3.0.339, with the signal to noise threshold set to 1.5.

202 Peaks6 software was also used. The reliability of the MS/MS largely depends on the detection of

203 the fragmented ions. All the sequencing was determined using the Mascot search engine with a

204 score of 40 or higher, and a probability of false identification of $<10^{-5}$; an effort was made to

205 manually check the identified ions in the sequencing outcome.

207 Results

\section{The variations in the hydroxylation of collagen}

The heterogeneity of the hydroxylation of collagen $\alpha$-chains can be observed at different

210 levels by mass-spectrometry (MS). The sequencing by MS is carried out on trypsin digested

211 peptides of collagen which usually range from 6-30 amino acid residues in length. The observed

212 mass of one tryptic peptide that has undergone heterogeneous hydroxylation will resemble a

213 mixture of species with mass differences of 16 (replacing $-\mathrm{H}$ by $-\mathrm{OH}$ ) or multiples of 16 . The

214 presence of such mixed species was frequently observed in MALDI MS spectra of a total 
215 collagen digest (Fig. 1). The exact number of such peak-clusters varies among different

216 collagens, and/or the different preparations of the same collagen. The observation of such peaks

217 by MALDI MS depends on the trypsin digestion reaction and the signal level in the MALDI MS

218 spectra. Only those peaks with the highest level of signal are labeled in Fig. 1; many others are

219 present with low signal levels. Although it is not possible to identify these peptides by MALDI

220 MS per se, given the widespread existence of peaks with mass variants of 16, it is unlikely for

221 these peaks to be caused by the coincidental mass variations of different tryptic peptides. Rather,

222 these peaks point to a mixed population of tryptic peptides with incomplete and/or 'over'

223 hydroxylation of amino acid residues. The MS/MS sequencing study further supports this

224 conclusion.

225

226 Fig 1. MALDI-TOF spectra of total trypsin digest. (A) Human collagen type III, (B) Human

227 collagen type I, (C) Rat collagen type I. Peaks A - E in panel (A) and panel (B) and A-F in panel

228 (C) are tryptic peptides of the corresponding collagens identified based on the agreement of their

229 molecular weight (+1 ion) with that of the 'theoretical value' (assuming all Y-Pro as Hyp). The

230 mass variants of 16 of each peak are labeled based on their mass differences from that of the

231 'theoretical value'.

232

233 2. The $O_{x}$ and the $P_{y}$ residues identified by MS/MS sequencing of the

234 collagens

235 For the clarity and the convenience of data presentation we will use $\mathrm{O}_{\mathrm{x}}$ (or X-Hyp) and $\mathrm{P}_{\mathrm{y}}$

236 (or Y-Pro), respectively, for a hydroxylated Pro in the $\mathrm{X}$ position and an unhydroxylated Pro in 
237 the Y-position to highlight the unusual hydroxylation results; the normal symbols of P (or Pro)

238 and O (or Hyp) are used for Pro and 4-hydroxyproline in X and Y positions, respectively. Even

239 by MS/MS sequencing, the exact modification often cannot be resolved with certainty with the

240 mass information alone. In case a +16 mass is observed for a fragment of pro-gly-pro or pro-pro-

241 gly sequence, for example, it is generally necessary to assume the hydroxylation of Pro is in the

242 Y-position and not in the X-position in order to resolve the mass variations. Such fragments are

243 common because of the high content of Pro in collagen and the proline-effect of MS/MS-

244 sequencing $(3,10,43-45)$. In compiling the sequencing data the 'theoretical mass' is calculated

245 assuming all Pro residues in the Y-position are hydroxylated. Thus, a mass variation of -16

246 reflects an incomplete hydroxylation of Y-Pro residues, while that of +16 indicates an additional

247 hydroxylation beyond the usual Hyp at Y-positions. In addition to Pro in an X position, a

248 modified Lys (Hyl) in a Y-position or an oxidized Met $\left(\mathrm{M}_{\mathrm{ox}}\right)$ would also cause a mass change of

$249+16$ compared to their unmodified counterpart (47). A C-terminal Y-position Lys of the peptides

250 can potentially be a hydroxylated Lys and contribute to the +16 mass variation. Considering the

251 7-fold decrease in trypsin susceptibility to Hyl relative to that of Lys, however, a C-terminal Hyl

252 of a tryptic digest is an unlikely event (48). The C-terminal Lys residues are, thus, usually taken

253 as one that is not hydroxylated with one exception: Hyl ${ }^{87}$ of the $\alpha 2$ chain of rat tail type I

254 collagen (see later sections). The hydroxylation of this Lys was supported unambiguously by the

$255+16$ data of fragmented ions: all Y-Pro residues of this tryptic peptide are all fully occupied and

256 there is no Pro in the X-position. The Lys in the equivalent position of human collagen was

257 found to be hydroxylated by other methods (3). Hyl will not be seen in the sequencing results if

258 glycosylated or cross-linked to neighboring peptides. 
In the following, we only report the $\mathrm{O}_{\mathrm{x}}$ and $\mathrm{P}_{\mathrm{y}}$ residues that are unambiguously supported

260 by a series of fragmented $b$ - and/or $y$ - ions. One typical example of unusual hydroxylation is

261 given in Fig 2. There are 3 Pro residues in this 19-residue peptide from position 435-453 of the

$262 \alpha_{1}(\mathrm{I})$ chain of collagen isolated from a single rat tail tendon $(\mathrm{srtt})$ : two in the X-position $\left(\mathrm{p}^{446}\right.$,

$263 \mathrm{p}^{449}$ ) and one in $\mathrm{Y}$-position $\left(\mathrm{p}^{444}\right)$. The tryptic digest of this particular region of the $\alpha 1(\mathrm{I})$ chain

264 was partitioned into three populations with different hydroxylation. The sequencing outcome in

265 Fig 2A reflects the expected hydroxylation pattern, with the $\mathrm{p}^{444}$ being hydroxylated and the mass

266 of the peptide the expected value of 1680.76 . The Hyp $\mathrm{H}^{444}$ is supported by the identification of a

267 nearly complete series of $\mathrm{y}$ - and b-ions and most directly by the $\mathrm{y}_{10}$ ion with a very strong signal.

268 The sequencing outcome of the second population indicate the peptide carries a mass variant of

$269+16$ compared to the theoretical value (Fig. 2B), and the extra hydroxylation is unambiguously

270 located on the $\mathrm{p}^{449}$ at the $\mathrm{X}$-position, directly supported by the +16 values of $\mathrm{y}_{5}$ and $\mathrm{y}_{6}$ ions

271 comparing to that in Fig 2A (i.e., the theoretical value). In the third case (Fig. 2C) the mass has a

$272-16$ variant, and again the strong $\mathrm{y}_{10}$ ion, as well as the -16 mass of the $\mathrm{y}_{12}$ and $\mathrm{y}_{13}$ ions

273 demonstrated that the $\mathrm{p}^{444}$ at the Y-position was not hydroxylated. Thus, there are three different

274 scenarios regarding Pro hydroxylation in this region: the one with expected Hyp ${ }^{444}$ in the Y-

275 position, the one with $\mathrm{O}_{\mathrm{x}}{ }^{449}$, and the one with $\mathrm{P}_{\mathrm{y}}{ }^{444}$. Since this particular collagen sample is

276 isolated from a single rat tail tendon, the heterogeneous patterns of the hydroxylation reflects the

277 natural variations of the Pro-hydroxylases and/or the variations accumulated over the

278 development of this organism.

280 Fig 2. The MS/MS spectra of tryptic peptide ${ }^{435}$ dgeagaqgapgpagpager of rat tail tendon

$281 \boldsymbol{\alpha 1}(\mathbf{I})$ chain (lower case stands for the sequence from the genes). Sequencing outcome from ion 
$832.38122^{+}\left(1664.7623^{+}\right)$(lower panel). The hydroxylation sites are shown as $\stackrel{\text { ox }}{\mathrm{P}}$. For clarity,

291 all collagen samples are given in the tables of the supplemental material S1. All the samples are

292 sequenced at least twice in order to evaluate the reproducibility of the results. The reproducible

293 findings are shown in boldface in the tables. In addition to the fragmentation data, the unusual

294 hydroxylation of the peptides in Tables 1-3 is unequivocally identified by the variations of their 295 masses $(\Delta m)$.

\section{The over hydroxylation and under-hydroxylation of type I collagen}

\section{from rat tail tendon}

The results in Table 1 revealed a range of variations of the hydroxylation in both the $\alpha 1$ 
304 peptides except that of residues 76-87 (peptide mass 1238.6052) are assigned to a specific X-

305 Hyp based on the fragmentation ions; the +16 mass between residues $76-87$ is assigned to the C-

306 terminal Lys since it is the only residue in that peptide that can be hydroxylated. The precise

307 location of the extra hydroxylation of peptide mass 2605.2529 (residues 145-174) of the $\alpha 2(\mathrm{I})$

308 chain was difficult to resolve since the terminal pro-lys residues were not fragmented; both are

309 the candidates for the hydroxylation (with a +16 mass). We are not aware of any other report on

310 the hydroxylation of this particular Lys. Since Lys is more likely to be cleaved by trypsin than

311 Hyl, we have tentatively assigned the hydroxylation site to be the Pro ${ }^{173}$ in the X-position, and

312 the $\boldsymbol{O}_{\boldsymbol{x}}{ }^{173}$ was shown in italic in Table 1 to highlight this uncertainty. Despite lacking a clear

313 resolution of the location of the extra hydroxylation, the same peptide was observed more than

314 once during multiple sequencing efforts as shown in the bold face in Table 1, which is

315 presumably related to its measurable presence in this rat tail sample. The Lys residue in the

316 equivalent position of the $\alpha 1(\mathrm{I})$ chain in the peptide of residues 145-174 was resolved

317 unambiguously, and for multiple times by the observation of the fragment having a terminal

318 unhydroxylated Lys. This peptide, however, was found to have an over hydroxylation site on X-

$319 \operatorname{Pro}^{155}\left(\mathbf{O}_{\mathbf{x}}{ }^{155}\right)$. Similarly, for peptide mass 2323.1313 (residues 658-684) of $\alpha 1(\mathrm{I})$ chain (Table 1),

320 the $\boldsymbol{O}_{x}{ }^{683}$ was assigned with uncertainty because the non-fragmented terminal Pro-Lys prevented

321 an unambiguous assignment of the unexpected hydroxylation site.

323 Table 1. Peptides of rat type I collagen with mass variants of 16 (the commercial sample)

\begin{tabular}{|l|l|l|l|l|}
\hline${\text { Ion } \text { mass }^{\mathrm{a}}}^{\mid} \Delta m^{\mathrm{b}}$ & Score $^{\mathrm{c}}$ & Unusual Hydroxylation & Sequence of Peptide $^{\mathrm{d}}$ \\
\hline \multicolumn{6}{|l|}{ The $\alpha 1(\mathrm{I})$ chain of rat collagen (commercial sample) } \\
\hline 1306.6386 & & 92 & & ${ }^{238}$ GPSGPQGPSGAOGPK \\
\hline
\end{tabular}


bioRxiv preprint doi: https://doi.org/10.1101/2021.04.12.439427; this version posted April 12, 2021. The copyright holder for this preprint (which was not certified by peer review) is the author/funder, who has granted bioRxiv a license to display the preprint in perpetuity. It is made available under aCC-BY 4.0 International license.

\begin{tabular}{|c|c|c|c|c|}
\hline 1322.6335 & +16 & 65 & $\mathbf{O}_{\mathbf{x}}{ }^{245}$ & ${ }^{238}{ }^{G P S G P Q G O} \mathbf{O}_{\mathbf{x}}$ SGAOGPK \\
\hline 1338.6284 & +32 & 58 & $\mathbf{O}_{x}{ }^{239}, \mathbf{O}_{x}{ }^{245}$ & ${ }^{238} \mathrm{GO}_{\mathbf{x}} \mathrm{SGPQGO}_{\mathbf{x}} \mathrm{SGAOGPK}$ \\
\hline 1328.6481 & -16 & 74 & $\mathbf{P}_{\mathbf{y}}^{\mathbf{8 0 4}}$ & ${ }^{793}$ GFOGLOGPSGEP $_{\mathbf{y}} \mathrm{GK}$ \\
\hline 1344.6430 & & 41 & & ${ }^{793}$ GFOGLOGPSGEOGK \\
\hline 1435.6812 & -16 & 43 & $\mathrm{P}_{\mathrm{y}}^{297}$ & ${ }^{295} \mathrm{GEP}_{\mathrm{y}} \mathrm{GPSGLOGPOGER}$ \\
\hline 1840.9188 & & 50 & & ${ }^{705}$ VGPOGPSGNAGPOGPOGPVGK \\
\hline 1856.9137 & +16 & 61 & $\mathbf{O}_{\mathbf{x}}{ }^{707}$ & ${ }^{705} \mathrm{VGO}_{\mathbf{x}} \mathrm{OGPSGNAGPOGPOGPVGK}$ \\
\hline 1872.9086 & +32 & 49 & $\mathbf{O}_{x}{ }^{707}, \mathbf{O}_{x}{ }^{719}$ or $\mathbf{O}_{x}{ }^{722}$ & 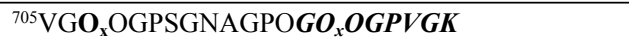 \\
\hline 1959.9519 & -16 & 87 & $\mathbf{P}_{\mathbf{y}}^{273}$ & ${ }^{271}$ GEP$_{\mathbf{y}}$ GPAGVQGPOGPAGEEGKR \\
\hline 1975.9468 & & 94 & & ${ }^{271}$ GEOGPAGVQGPOGPAGEEGKR \\
\hline 2014.9689 & & 41 & & ${ }^{375}$ TGPOGPAGQDGROGPAGPOGAR \\
\hline 2030.9639 & +16 & 50 & $\mathrm{O}_{\mathrm{x}}^{377}$ & ${ }^{375} \mathrm{TGO}_{\mathrm{x}} \mathrm{OGPAGQDGROGPAGPOGAR}$ \\
\hline 2120.9955 & -16 & 98 & $\mathbf{P}_{\mathbf{y}}^{771}$ & ${ }^{757}$ GSOGADGPAGSOGTP $_{\mathbf{y}}$ GPQGIAGQR \\
\hline 2136.9905 & & 84 & & $\begin{array}{l}{ }^{757} \text { GSOGADGPAGSOGTOGPQGIAGQR } \\
\text {. }\end{array}$ \\
\hline 2169.0571 & -16 & 57 & $\mathrm{P}_{\mathrm{y}}^{876}$ & ${ }^{859}$ GETGPAGPOGAOGAOGAP $_{\mathrm{y}}$ GPVGPAGK \\
\hline 2185.0520 & & 45 & & ${ }^{859}$ GETGPAGPOGAOGAOGAOGPVGPAGK \\
\hline 2307.1364 & & 58 & & ${ }^{658}$ GDAGPOGPAGPAGPOGPIGNVGAOGPK \\
\hline 2323.1313 & +16 & 79 & $\boldsymbol{O}_{x}{ }^{683}$ & ${ }^{658} \mathrm{GDAGPOGPAGPAGPOGPIGNVGAOG} O_{x} K$ \\
\hline 2316.0487 & & 53 & & ${ }^{193}$ GEOGPOGPAGAAGPAGNOGADGQOGAK \\
\hline 2332.0436 & +16 & 79 & $\mathbf{O}_{\mathrm{x}}{ }^{206}$ & ${ }^{193}$ GEOGPOGPAGAAGO ${ }_{\mathbf{x}}$ AGNOGADGQOGAK \\
\hline 2548.2063 & & 101 & & ${ }^{145}$ GNDGAVGAAGPOGPTGPTGPOGFOGAAGAK \\
\hline 2564.2012 & +16 & 54 & $\mathbf{O}_{\mathrm{x}}{ }^{155}$ & ${ }^{145}$ GNDGAVGAAGO ${ }_{\mathbf{x}}$ OGPTGPTGPOGFOGAAGAK \\
\hline 2679.2394 & -16 & 42 & $\mathbf{P}_{\mathbf{y}}{ }^{948}$ & י344GFSGLQGPOGSOGSP ${ }_{y}$ GEQGPSGASGPAGPR \\
\hline 2695.2343 & & 127 & & ${ }^{934}$ GFSGLQGPOGSOGSOGEQGPSGASGPAGPR \\
\hline \multicolumn{5}{|c|}{ The $\alpha 2$ (I) chain of rat collagen (commercial sample) } \\
\hline 1238.6052 & +16 & 58 & $\mathbf{H y l}^{87}$ & ${ }^{76}$ GFOGTOGLOGFK $_{\mathbf{x}}$ \\
\hline 1560.8129 & -16 & 102 & $\mathbf{P}_{\mathbf{y}}{ }^{891}$ & ${ }^{889} \mathrm{GEP}_{\mathrm{y}} \mathrm{GPAGSVGPVGAVGPR}$ \\
\hline 1576.8078 & & 59 & & ${ }^{889} \mathrm{GEOGPAGSVGPVGAVGPR}$ \\
\hline 1576.7714 & -32 & 79 & $\mathbf{P}_{\mathbf{y}}{ }^{294}, \mathbf{P}_{\mathbf{y}}{ }^{297}$ & ${ }^{292}$ GSP $_{\mathbf{y}}$ GEP $\mathbf{y}_{\mathrm{y}}$ GSAGPAGPOGLR \\
\hline 1592.7663 & -16 & 58 & $\mathbf{P}_{\mathbf{y}}^{\mathbf{2 9 7}}$ & ${ }^{292}$ GSOGEP$_{\mathrm{y}}$ GSAGPAGPOGLR \\
\hline
\end{tabular}




\begin{tabular}{|c|c|c|c|c|}
\hline 1608.7612 & & 76 & & ${ }^{292}$ GSOGEOGSAGPAGPOGLR \\
\hline 1781.7937 & -16 & 69 & $\mathbf{P}_{\mathbf{y}}{ }^{273}$ & ${ }^{271}$ GEP \\
\hline 1937.8948 & -16 & 115 & $\mathbf{P}_{\mathbf{y}}{ }^{273}$ & ${ }^{271} \mathrm{GEP}_{\mathrm{y}} \mathrm{GSAGAQGPOGPSGEEGKR}$ \\
\hline 2368.0648 & -16 & 41 & $\mathbf{P}_{\mathbf{y}}{ }^{273}$ & ${ }^{265}$ GETGNKGEP \\
\hline 2384.0597 & & 60 & & ${ }^{265}$ GETGNKGEOGSAGAQGPOGPSGEEGK \\
\hline 1833.8977 & +16 & 47 & $\mathbf{O}_{\mathbf{x}}{ }^{707}$ & ${ }^{705} \mathrm{TGO}_{\mathbf{x}} \mathrm{OGPSGITGPOGPOGAAGK}$ \\
\hline 2605.2529 & +16 & 80 & $O_{x}^{173}$ & ${ }^{145}$ GSDGSVGPVGPAGPIGSAGPOGFOGAOG $\boldsymbol{O}_{x} K$ \\
\hline 2971.512 & -16 & 76 & $\mathrm{P}_{\mathrm{y}}{ }^{762}$ & ${ }^{757}$ GPSGEP ${ }_{\text {y }}$ TTGPOGTAGPQGLLGAOGILGLOGSR \\
\hline 2987.5069 & & 48 & & ${ }^{757}$ GPSGEOGTTGPOGTAGPQGLLGAOGILGLOGSR \\
\hline
\end{tabular}

a: The mass of the single charged ion used to identify each peptide. The sequencing results of most of the peptides

327 b: The mass differences compared to the 'theoretical' assuming all Pro in the Y positions are hydroxylated.

328 c: The score of Mascot search engine (see Material and Methods).

329 d: Unexpected hydroxylation of X-Pro and unhydroxylated Y-Pro are shown as $\mathrm{O}_{\mathrm{x}}$ and $\mathrm{P}_{\mathrm{y}}$, respectively; those

330 observed in more than one sequencing effort and/or in both the commercial and the rrt samples (see text) are in bold; 331 those with uncertainties are shown in italic (see text).

334 peptide. For example, the peptide with ion mass 1306.6386 (residues 238-252) coexists with the

335 two over-hydroxylated species: a +16 species with mass 1322.6335 and a +32 species with mass

3361338.6284 carrying, respectively, one and two extra hydroxylation sties. Due to the

337 unpredictable and complex nature of the ionization process of MS and MS/MS, it is difficult to

338 quantify the relative percentages of the various hydroxylated species by MS alone. In a few

339 cases, such as for the $\alpha 2$ chain peptide with mass 2605.2529 (residues 145-174) only a single

340 population with an extra hydroxylation was sequenced. Despite two sequencing efforts, a species

341 with the theoretical mass was not observed. This lack of detection, however, does not rule out the

342 existence of this population in the sample per se. This species may fail to be sequenced to an 
343 acceptable quality either due to poor ionization and/or fragmentation, or may have failed to be

344 identified due to unexpected post-translational modifications. One limitation of mass-spec data

345 interpretation is the inability to draw conclusions about peptides that are not selected for

346 fragmentation.

Concurrently, incomplete hydroxylation was found in six and four regions, respectively,

348 of the $\alpha 1(\mathrm{I})$ and the $\alpha 2$ (I) chains, located in the regions of residues 271-291, 295-309, 757-780,

$349793-806,859-884$ and 934-963 of the $\alpha 1(\mathrm{I})$ chain, and of residues 271-290, 292-309 (having 2

350 different $\mathrm{P}_{\mathrm{y}}$ residues), 757-789 and 889-906 of the $\alpha 2(\mathrm{I})$. Remarkably, among the 11 detected $\mathrm{P}_{\mathrm{y}}$

351 residues in both $\alpha$ chains, seven of them were found in the triplet $\mathrm{GEP}_{\mathrm{y}}$.

hydroxylation between the $\alpha 1(\mathrm{I})$ and $\alpha 2(\mathrm{I})$ chains. The region between residues 705 and 725 in

354 both $\alpha$ chains contain multiple $\mathrm{O}_{\mathrm{x}}$ residues: $\mathrm{O}_{\mathrm{x}}{ }^{707}$ and $\mathrm{O}_{\mathrm{x}}{ }^{722}$ in $\alpha 1(\mathrm{I})$ chain and $\mathrm{O}_{\mathrm{x}}{ }^{707}$ in $\alpha 2(\mathrm{I})$

355 chain. Similarly, some of the $\mathrm{P}_{\mathrm{y}}$ residues appear located in similar regions of both $\alpha$ chains as

356 well: $\mathrm{P}_{\mathrm{y}}{ }^{273}$ between residues $271-291, \mathrm{P}_{\mathrm{y}}{ }^{294}$ and $\mathrm{P}_{\mathrm{y}}{ }^{297}$ between residues $295-309, \mathrm{P}_{\mathrm{y}}{ }^{762}$ and $\mathrm{P}_{\mathrm{y}}{ }^{771}$

357 between residues 757-789. Combining the observations of different peptides from both $\alpha$ chains,

358 the region of residues 271-309 in both $\alpha 1(\mathrm{I})$ and $\alpha 2(\mathrm{I})$ chains stands out as a particularly poorly

359 hydroxylated region, missing two to three expected Hyp residues in the Y-positions of each $\alpha$

360 chain.

The finding of such a wide range of variations in hydroxylation of the type I chain is

362 rather unexpected. The purity and the purification procedures of this commercial sample were

363 called into question. In order to get a better understanding of the origin of the heterogeneity we

364 purified the type I collagen from a single rat tail tendon (srtt). Interestingly, the sequencing result 
365 of this srtt sample turns out to be remarkably similar (Table 2). The 2 observed $\mathrm{O}_{\mathrm{x}}$ residues in the

$366 \alpha 2(\mathrm{I})$ of the commercial sample and all but two $\left(\mathrm{O}_{\mathrm{x}}{ }^{206}\right.$ and $\left.\mathrm{O}_{\mathrm{x}}{ }^{377}\right)$ in the $\alpha 1(\mathrm{I})$ chain (Table 1)

367 were reproduced in the srtt sample. Similarly, more than half of the $\mathrm{P}_{\mathrm{y}}$ residues found in the

368 commercial sample were also observed in the srtt sample. This srtt sample appeared to be

369 particularly over-hydroxylated having $11 \mathrm{O}_{\mathrm{x}}$ residues in each $\alpha$ chain. The content of $\mathrm{P}_{\mathrm{y}}$ is also

370 higher: 10 and $9 \mathrm{P}_{\mathrm{y}}$ residues, respectively, were found in the $\alpha 1(\mathrm{I})$ and $\alpha 2(\mathrm{I})$ chains. The

371 noticeably more heterogeneous hydroxylation pattern of this srtt sample, especially that for the

$372 \alpha 2(\mathrm{I})$ chain, may relate to the better overall sequencing outcome of the sample reflected, in part,

373 by the better sequence coverage of this $\alpha 2$ chain (Fig. 3 and S1 Tables S1-S6). The identified $\mathrm{O}_{\mathrm{x}}$

374 residues of the $\alpha 1$ (I) chain of the srtt sample include the well-known 3-Hyp $\mathrm{O}_{\mathrm{x}}{ }^{986}$; this section of

375 the $\alpha 1(\mathrm{I})$ chain of the commercial sample was not sequenced. Another interesting peptide with

376 an additional Hyp of interest is the seven-residue peptide from the N-telopeptide region

377 preceding the triple helical domain (ion mass 1452.7264). The Met residue in this fragment

378 appears to be oxidized based on the detection of $\mathrm{M}_{\mathrm{ox}}$ with neutral loss. In addition to the $\mathrm{M}_{\mathrm{ox}}$,

379 the Pro in the N-telopeptide appears to be hydroxylated (the $\mathrm{P}^{*}$ ). Since this Pro proceeds a Gly

380 residue, which characterizes the canonical hydroxylation site of the prolyl-hydroxylase (C-P4H),

381 its hydroxylation, although never reported before, probably does not come as too much of a

382 surprise.

Table 2A. Peptides of type I collagen from a single rat tail tendon with mass variants of 16

\begin{tabular}{|l|l|l|l|l|}
\hline Ion mass $^{\mathrm{a}}$ & $\Delta m^{\mathrm{b}}$ & Score $^{\mathrm{c}}$ & $\begin{array}{l}\text { Unusual } \\
\text { Hydroxylation }\end{array}$ & Peptide $^{\mathrm{d}}$ \\
\hline \multicolumn{5}{|l|}{ The $\alpha 1$ chain of type I collagen isolated from a single rat tail tendon (srtt) } \\
\hline 1242.5961 & -16 & 63 & $\mathrm{P}_{\mathrm{y}}{ }^{369}$ & ${ }^{361}$ GLTGSOGSP ${ }_{\mathrm{y}}$ GPDGK \\
\hline 1322.6335 & +16 & 76 & $\mathbf{O}_{\mathbf{x}}{ }^{239}$ & ${ }^{238} \mathrm{GO}_{\mathbf{x}} \mathrm{SGPQGPSGAOGPK}$ \\
\hline
\end{tabular}


bioRxiv preprint doi: https://doi.org/10.1101/2021.04.12.439427; this version posted April 12, 2021. The copyright holder for this preprint (which was not certified by peer review) is the author/funder, who has granted bioRxiv a license to display the preprint in perpetuity. It is made available under aCC-BY 4.0 International license.

\begin{tabular}{|c|c|c|c|c|}
\hline 1338.6284 & +32 & 76 & $\mathbf{O}_{\mathbf{x}}^{239}, \mathrm{O}_{\mathrm{x}}^{251}$ & ${ }^{238} \mathrm{GO}_{\mathbf{x}} \mathrm{SGPQGPSGAOGO}_{\mathrm{x}} \mathrm{K}$ \\
\hline 1354.6233 & +48 & 49 & $\mathbf{O}_{\mathbf{x}}{ }^{239}, \mathbf{O}_{\mathbf{x}}{ }^{245}, \mathrm{O}_{\mathrm{x}}{ }^{251}$ & ${ }^{238} \mathrm{GO}_{\mathbf{x}} \mathrm{SGPQGO}_{\mathbf{x}} \mathrm{SGAOG}_{x} K$ \\
\hline 1452.7264 & & 65 & & ${ }^{-7}$ SAGVSVPGPMGPSGPR \\
\hline 1468.7213 & +16 & 51 & $\mathrm{M}_{\mathrm{ox}}{ }^{3}$ & ${ }^{-7}$ SAGVSVPGPM ${ }_{0 x}$ GPSGPR \\
\hline 1484.7162 & +32 & 40 & $\mathrm{P}^{-1 *}, \mathrm{M}_{\mathbf{o x}}{ }^{3}$ & ${ }^{-7}$ SAGVSVP*GPM ${ }_{o x}$ GPSGPR \\
\hline 1574.8173 & -16 & 86 & $\mathrm{P}_{\mathrm{y}}{ }^{600}$ & ${ }^{586}$ GLTGPIGPOGPAGAP $_{\mathrm{y}} \mathrm{GDK}$ \\
\hline 1590.8122 & & 42 & & ${ }^{586}$ GLTGPIGPOGPAGAOGDK \\
\hline 1561.7969 & +16 & 40 & $\mathrm{O}_{\mathrm{x}}^{986}$ & ${ }^{975}$ DGLNGLOGPIGO $_{x} \mathrm{OGPR}$ \\
\hline 1872.9086 & +32 & 49 & $\mathbf{O}_{\mathbf{x}}{ }^{707}, \mathrm{O}_{\mathrm{x}}{ }^{719}$ & ${ }^{705} \mathrm{VGO}_{\mathbf{x}} \mathrm{OGPSGNAGPOGO} \mathrm{OGPVGK}$ \\
\hline 1888.9035 & +48 & 48 & $\mathbf{O}_{\mathbf{x}}{ }^{707}, \mathrm{O}_{\mathrm{x}}{ }^{716}, \mathbf{O}_{\mathbf{x}}{ }^{719}$ & ${ }^{705}$ VGO $_{\mathbf{x}} \mathrm{OGPSGNAGO}_{\mathbf{x}} \mathrm{OGO}_{\mathbf{x}} \mathrm{OGPVGK}$ \\
\hline 1664.7623 & -16 & 88 & $\mathrm{P}_{\mathrm{y}}^{444}$ & ${ }^{435}$ DGEAGAQGAP $_{\mathrm{y}}$ GPAGPAGER \\
\hline 1680.7572 & & 96 & & ${ }^{435}$ DGEAGAQGAOGPAGPAGER \\
\hline 1696.7521 & +16 & 92 & $\mathrm{O}_{\mathrm{x}}^{449}$ & ${ }^{435}$ DGEAGAQGAOGPAGO $_{x}$ AGER \\
\hline 1800.8697 & -32 & 105 & $\mathrm{P}_{\mathrm{y}}^{825}, \mathrm{P}_{\mathrm{y}}{ }^{831}$ & ${ }^{817}$ GPOGPMGPP $_{\mathrm{y}}$ GLAGPP $_{\mathrm{y}}$ GESGR \\
\hline 1816.8647 & -16 & 125 & $\mathrm{P}_{\mathrm{y}}^{825}, \mathrm{P}_{\mathrm{y}}{ }^{831}, \mathrm{M}_{\mathrm{ox}}{ }^{822}$ & ${ }^{817} \mathrm{GPOGPM}_{\mathrm{ox}} \mathrm{GPP}_{\mathrm{y}} \mathrm{GLAGPP} \mathrm{gESGR}$ \\
\hline 1803.8508 & -16 & 77 & $\mathbf{P}_{\mathrm{y}}{ }^{273}$ & ${ }^{271}$ GEP$_{\mathbf{y}}$ GPAGVQGPOGPAGEEGK \\
\hline 1819.8457 & & 82 & & ${ }^{271}$ GEOGPAGVQGPOGPAGEEGK \\
\hline 2105.0006 & -32 & 78 & $\mathrm{P}_{\mathrm{y}}{ }^{759}, \mathbf{P}_{\mathbf{y}}{ }^{771}$ & ${ }^{757}$ GSP $_{\mathrm{y}}$ GADGPAGSOGTP ${ }_{\mathrm{y}}$ GPQGIAGQR \\
\hline 2339.1262 & +32 & 40 & $\mathrm{O}_{\mathrm{x}}{ }^{668}, \boldsymbol{O}_{x}{ }^{683}$ & 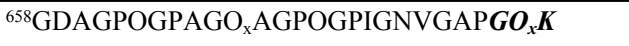 \\
\hline 2548.2063 & & 58 & & ${ }^{145}$ GNDGAVGAAGPOGPTGPTGPOGFOGAAGAK \\
\hline 2564.2012 & +16 & 96 & $\mathbf{O}_{\mathbf{x}}{ }^{155}$ & ${ }^{145}$ GNDGAVGAAGO $_{\mathbf{x}} \mathrm{OGPTGPTGPOGFOGAAGAK}$ \\
\hline 2663.2444 & -32 & 96 & $\mathrm{P}_{\mathrm{y}}{ }^{945}, \mathbf{P}_{\mathrm{y}}{ }^{948}$ & ${ }^{934}{ }^{34 F S G L Q G P O G S P}$ GSP $_{\mathbf{y}}$ GEQGPSGASGPAGPR \\
\hline 2679.2394 & -16 & 105 & $\mathbf{P}_{\mathbf{y}}^{\mathbf{y}^{448}}$ & $\begin{array}{l}{ }^{934} \text { GFSGLQGPOGSOGSP } \\
\text { yEQGPSGASGPAGPR }\end{array}$ \\
\hline 2695.2343 & & 62 & & 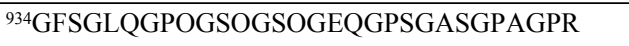 \\
\hline
\end{tabular}

Footnote:

385 a: The mass of the single charged ion used to identify each peptide. The sequencing results of most of the peptides 386 are based on the fragmentation of the double charged species (see below).

387 b: The mass differences compared to the 'theoretical' assuming all Pro in the Y positions are hydroxylated.

388 c: The score of Mascot search engine (see Material and Methods).

d: Unexpected hydroxylation of X-Pro and unhydroxylated Y-Pro are shown as $\mathrm{O}_{\mathrm{x}}$ and $\mathrm{P}_{\mathrm{y}}$, respectively;

391 bold; those with uncertainties are shown in italic (see text). 
394 Table 2B. Peptides of type I collagen from a single rat tail tendon with mass variants of 16

\begin{tabular}{|c|c|c|c|c|}
\hline Ion mass ${ }^{\mathrm{a}}$ & $\Delta m^{\mathrm{b}}$ & Score ${ }^{c}$ & $\begin{array}{l}\text { Unusual } \\
\text { Hydroxylation }\end{array}$ & Peptide $^{\text {d }}$ \\
\hline \multicolumn{5}{|c|}{ The $\alpha 2$ chain of type I collagen isolated from a single rat tail tendon ( $\mathrm{srtt})$} \\
\hline 868.4635 & & 51 & & 907GPSGPQGIR \\
\hline 884.4585 & +16 & 46 & $\mathrm{O}_{\mathrm{x}}^{908}$ & ${ }^{907} \mathrm{GO}_{\mathrm{x}}$ SGPQGIR \\
\hline 937.5102 & & 52 & & ${ }^{964}$ GPAGPSGPIGK \\
\hline 953.5051 & +16 & 51 & $\mathrm{O}_{\mathrm{x}}{ }^{968}$ & ${ }^{964}$ GPAGO $_{x}$ SGPIGK \\
\hline 1068.5684 & -16 & 71 & $\mathrm{P}_{\mathrm{y}}^{258}$ & ${ }^{253}$ GLVGEP yPAGSK \\
\hline 1084.5633 & & 70 & & ${ }^{253}$ GLVGEOGPAGSK \\
\hline 1175.5691 & +16 & 79 & $O_{x}^{407}$ & 397GEAGNIGFOGPK \\
\hline 1187.6280 & -16 & 54 & $\mathrm{P}_{\mathrm{y}} 981$ & ${ }^{978}$ SGHP $_{\mathrm{y}}$ GPVGPAGVR \\
\hline 1238.6052 & +16 & 64 & $\mathrm{Hyl}^{87}$ & ${ }^{76}$ GFOGTOGLOGFK $_{\mathbf{0 x}}$ \\
\hline 1437.7485 & -16 & 79 & $\mathrm{P}_{\mathrm{y}}^{486}$ & ${ }^{484} \mathrm{GLP}_{\mathrm{y}} \mathrm{GEFGLOGPAGPR}$ \\
\hline 1453.7434 & & 75 & & ${ }^{484}$ GLOGEFGLOGPAGPR \\
\hline 1469.7383 & +16 & 110 & $\mathrm{O}_{\mathrm{x}}^{494}$ & ${ }^{484}$ GLOGEFGLOGO $_{x}$ AGPR \\
\hline 1490.7122 & & 59 & & 741TGEIGASGPOGFAGEK \\
\hline 1506.7071 & +16 & 67 & $\mathrm{O}_{\mathrm{x}}{ }^{749}$ & ${ }^{741}$ TGEIGASGO ${ }_{\mathrm{x}}$ OGFAGEK \\
\hline 1560.8129 & -16 & 102 & $\mathbf{P}_{\mathbf{y}}{ }^{891}$ & ${ }^{889}$ GEP$_{y}$ GPAGSVGPVGAVGPR \\
\hline 1576.8078 & & 110 & & ${ }^{889}$ GEOGPAGSVGPVGAVGPR \\
\hline 2025.0373 & -16 & 82 & $\mathbf{P}_{\mathbf{y}}{ }^{891}$ & ${ }^{885}$ HGNRGEP $_{\mathbf{y}}$ GPAGSVGPVGAVGPR \\
\hline 2041.0322 & & 76 & & ${ }^{885}$ HGNRGEOGPAGSVGPVGAVGPR \\
\hline 1576.7714 & -32 & 76 & $\mathbf{P}_{\mathbf{y}}^{294}, \mathbf{P}_{\mathbf{y}}^{297}$ & ${ }^{292}$ GSP $_{\mathbf{y}}$ GEP $\mathbf{y}$ GSAGPAGPOGLR \\
\hline 1592.7663 & -16 & 85 & $\mathbf{P}_{\mathbf{y}}^{\mathbf{2 9 4}}$ & ${ }^{292}$ GSP $_{\mathbf{y}}$ GEOGSAGPAGPOGLR \\
\hline 1608.7612 & & 88 & & ${ }^{292}$ GSOGEOGSAGPAGPOGLR \\
\hline 1624.7562 & +16 & 94 & $\mathrm{O}_{\mathrm{x}}{ }^{302}$ & ${ }^{292}$ GSOGEOGSAGO $_{x}$ AGPOGLR \\
\hline 1748.8674 & -16 & 69 & $\mathbf{P}_{\mathbf{y}}{ }^{297}$ & ${ }^{291}$ RGSOGEP $\mathbf{y}$ GSAGPAGPOGLR \\
\hline 1764.8624 & & 50 & & ${ }^{291}$ RGSOGEOGSAGPAGPOGLR \\
\hline
\end{tabular}




\begin{tabular}{|c|c|c|c|c|}
\hline 1599.8238 & -16 & 87 & $\mathrm{P}_{\mathrm{y}}{ }^{183}$ & ${ }^{175}$ GELGPVGNP $_{\mathrm{y}}$ GPAGPAGPR \\
\hline 1615.8187 & & 105 & & ${ }^{175}$ GELGPVGNOGPAGPAGPR \\
\hline 1781.7937 & -16 & 85 & $\mathbf{P}_{\mathrm{y}} \mathbf{2 7 3}^{273}$ & ${ }^{271}$ GEP$_{\mathbf{y}}$ GSAGAQGPOGPSGEEGK \\
\hline 1797.7886 & & 94 & & ${ }^{271}$ GEOGSAGAQGPOGPSGEEGK \\
\hline 1817.9028 & & 52 & & ${ }^{705}$ TGPOGPSGITGPOGPOGAAGK \\
\hline 1833.8977 & +16 & 69 & $\mathbf{O}_{\mathbf{x}}{ }^{707}$ & ${ }^{705} \mathrm{TGO}_{\mathbf{x}} \mathrm{OGPSGITGPOGPOGAAGK}$ \\
\hline 1849.8926 & +32 & 89 & $\mathbf{O}_{x}{ }^{707}, \mathbf{O}_{x}{ }^{716}$ & ${ }^{705} \mathrm{TGO}_{\mathbf{x}} \mathrm{OGPSGITG \mathbf {O } _ { \mathbf { x } } \text { OGPOGAAGK }}$ \\
\hline 1865.8876 & +48 & 97 & $\mathbf{O}_{\mathbf{x}}{ }^{707}, \mathbf{O}_{\mathbf{x}}{ }^{716}, \mathbf{O}_{\mathbf{x}}{ }^{719}$ & ${ }^{705} \mathrm{TGO}_{\mathbf{x}} \mathrm{OGPSGITGO} \mathrm{OGGO}_{\mathbf{x}} \mathrm{OGAAGK}$ \\
\hline 2589.2580 & & 112 & & ${ }^{145}$ GSDGSVGPVGPAGPIGSAGPOGFOGAOGPK \\
\hline 2605.2529 & +16 & 103 & $\mathbf{O}_{\mathbf{x}}{ }^{173}$ & ${ }^{145}$ GSDGSVGPVGPAGPIGSAGPOGFOGAOG $\boldsymbol{O}_{x} K$ \\
\hline 2621.2478 & +32 & 51 & $\mathrm{O}_{\mathrm{x}}{ }^{164}, \mathbf{O}_{\mathbf{x}}{ }^{173}$ & ${ }^{145} \mathrm{GSDGSVGPVGPAGPIGSAGO}_{\mathrm{x}} \mathrm{OGFOGAOG} \boldsymbol{x}_{x} K$ \\
\hline 3045.4257 & -16 & 78 & $\mathrm{P}_{\mathrm{y}}^{552}$ & ${ }^{520}$ GPSGAOGPDGNKGEAGAVGAOGSAGASGPGGLP $\mathrm{y}$ GER \\
\hline 3077.4155 & +16 & 76 & $\mathrm{O}_{\mathrm{x}}{ }^{548}$ & ${ }^{520}$ GPSGAOGPDGNKGEAGAVGAOGSAGASGO $_{x}$ GGLOGER \\
\hline
\end{tabular}

396 a: The mass of the single charged ion used to identify each peptide. The sequencing results of most of the peptides are based on the fragmentation of the double charged species (see below).

398 b: The mass differences compared to the 'theoretical' assuming all Pro in the Y positions are hydroxylated.

c: The score of Mascot search engine (see Material and Methods).

d: Unexpected hydroxylation of X-Pro and unhydroxylated Y-Pro are shown as $\mathrm{O}_{\mathrm{x}}$ and $\mathrm{P}_{\mathrm{y}}$, respectively; those observed in more than one sequencing effort and/or in both the commercial and the rrt samples (see text) are in bold; those with uncertainties are shown in italic (see text).

407 pattern having 1 to $3 \mathrm{O}_{\mathrm{x}}$ residues in both chains. By comparing to the commercial sample, 
411 sequences: none of the equivalent X-residues of the $\alpha 2(\mathrm{I})$ chain where an $\mathrm{O}_{\mathrm{x}}$ is observed in the

$412 \alpha 1(\mathrm{I})$ chain is Pro. The poorly hydroxylated region of residues 271-309 is also under-

413 hydroxylated in this srtt sample, lacking 1 and 3 expected Y-Hyps, respectively, in the $\alpha 1(\mathrm{I})$ and

414 the $\alpha 2(\mathrm{I})$ chains. Other $\mathrm{P}_{\mathrm{y}}$ residues that are frequently observed in both samples are $\mathrm{P}_{\mathrm{y}}{ }^{771}$ and

$415 \quad \mathrm{P}_{\mathrm{y}}{ }^{948}$ of the $\alpha 1(\mathrm{I})$ chain, and $\mathrm{P}_{\mathrm{y}}{ }^{891}$ of the $\alpha 2(\mathrm{I})$ chain.

In fact, the sequenced peptides of the commercial sample in Table 1 appear almost as a

417 subset of that included in Table 2A and 2B of the srtt sample. Thus, on this account, the

418 commercial samples are quite representative of the averaged features of PTMs of collagens from

419 the type I collagen of the rat tail tendon. All together combining the results of the two samples of

420 type I collagen we have identified a total of $13 \mathrm{O}_{\mathrm{x}}$ in the $\alpha 1$ (I) chain and 11 in the $\alpha 2(\mathrm{I})$ chains,

421 also 13 and $10 \mathrm{P}_{\mathrm{y}}$ residues, respectively, in the $\alpha 1(\mathrm{I})$ and $\alpha 2(\mathrm{I})$ chains. The abnormal

422 hydroxylation sites detected from both samples are mapped out on the sequences of the $\alpha$-chains

423 arranged in D-periodicity in Figure 3. The sites of $\mathrm{O}_{\mathrm{x}}$ appear to be scattered rather uniformly

424 throughout the $\alpha$-chains except the two identified regions of highly variable hydroxylation

425 patterns (HVRs): the N-terminal highly variable region (N-HVR) of residues 238-252 of the $\alpha 1(\mathrm{I})$

426 chain, and the C-terminal highly variable region (C-HVR) of residues $705-725$ of both $\alpha$ chains.

427 The $\mathrm{O}_{\mathrm{x}}{ }^{155}$ of the $\alpha 1(\mathrm{I})$ chain is the only unexpected hydroxylation outside the HVRs that has

428 been observed multiple times in both samples. The $\mathrm{P}_{\mathrm{y}}$ residues also seem to cluster: in addition to

429 residues 271-302 mentioned above, regions of residues 941-950 and 821-840 of the $\alpha 1(\mathrm{I})$ chain,

430 and 757-780 of both $\alpha 1$ and the $\alpha 2$ chains all have multiple $\mathrm{P}_{\mathrm{y}}$ residues (Figure 3, Tables $1,2 \mathrm{~A}$

431 and 2B). 
433 Figure 3. The mapping of individual unexpected hydroxylation sites on the $\alpha$ chains of

434 collagen. Sequences of the $\alpha_{1}(\mathrm{I})$ and $\alpha_{2}(\mathrm{I})$ chains of human (H1A1 and H1A2, respectively), the

$435 \alpha_{1}(\mathrm{I})$ and the $\alpha_{2}(\mathrm{I})$ chains of rat (R1A1 and R1A2, respectively), and the $\alpha 1$ (III) chains of

436 human (H3A1) were arranged by the $D$-periodicity according to Di Lullo et al (49): the $4 D$ -

437 periods are highlighted by a colored bar of grey, yellow, cyan, and magenta, respectively; the 0.6

438 D is marked by the colored bar of green. The Gly-X-Y triplets including an $\mathrm{O}_{\mathrm{x}}$ are in grey

439 highlight. The $\mathrm{P}_{\mathrm{y}}$ residues are lighted in red in the tripeptide unit of Y-Gly-X in order to reflect

440 the potential connection with the enzyme selectivity of C-P4H (see text). The entire segment of

441 the three highly variable regions ( $\mathrm{N}$ - or $\mathrm{C}-\mathrm{HVR}$, see text) with multiple $\mathrm{O}_{\mathrm{x}}$ residues are boxed.

442 The hydroxylated proline in the telopeptide is $\mathrm{P}^{*}$. Hydroxylysines and the Gly-Pro-Lys tripeptide

443 where the hydroxylation could not be precisely located between the Pro-Lys residues at the C-

444 terminus of a peptide (see text) are highlighted in yellow with Lys in green font. The oxidized

445 methionines are in yellow colored font. In all cases the PTMs observed from more than one

446 detection/sample preparation were shown in bold font. Not sequenced regions are in faint grey.

447 The amino acid sequence of the five collagen $\alpha$ chains were adapted from UniProt database.

4. Human collagen type I and type III.

The detected unusual hydroxylation sites of human collagen type I and type III are

451 summarized in Table 3. Only the primary 3-Hyp at position $986\left(\mathrm{O}_{\mathrm{x}}{ }^{986}\right)$ of $\alpha 1(\mathrm{I})$ was found as

452 the X-Hyp in human type I collagen (Table 3A). Despite multiple sequencing efforts the peptide

453 containing Pro ${ }^{707}$ of $\alpha 2(\mathrm{I})$, one of the class-2 X-Hyp reported by Eyre and colleagues, was not

454 sequenced. The Pro ${ }^{707}$ of $\alpha 1$ (I) was sequenced but was found not hydroxylated in spite of the 
455 nearly identical amino acid sequences in this region between the two $\alpha$-chains (Fig 3 ). The

456 residue $\mathrm{Met}^{822}$ appears to be oxidized (Table 3A). The oxidation of Met is not a regular post-

457 translational modification but an oxidation event usually found in cells under stress; it can also

458 occur with sample handling $(47,50)(51)$. A few cases of incomplete hydroxylations were

459 observed for both the $\alpha 1(\mathrm{I})$ chain and the $\alpha 2(\mathrm{I})$ chain. In general, the sequencing of the human

460 type I collagen sample appeared to be rather clean, with only a low degree of unexpected

461 modifications.

462

463 Table 3. Peptides with mass variants of 16 in human collagen

\begin{tabular}{|c|c|c|c|c|}
\hline $\operatorname{Ion}_{\operatorname{mass}}{ }^{\mathrm{a}}\left(\mathrm{m} / \mathrm{z}^{+1}\right)$ & $\Delta m^{\mathrm{b}}$ & Score $^{\mathrm{c}}$ & $\begin{array}{l}\text { Unusual } \\
\text { Hydroxylation }\end{array}$ & Peptide $^{d}$ \\
\hline \multicolumn{5}{|c|}{ A. Human collagen type I } \\
\hline \multicolumn{5}{|l|}{$\alpha 1$ chain } \\
\hline 1561.7969 & +16 & 65 & $\mathrm{O}_{\mathrm{x}}^{986}$ & ${ }^{975}$ DGLNGLOGPIGO $_{x}$ OGPR \\
\hline 1832.8596 & & 78 & $\mathrm{M}_{\mathrm{ox}}^{822}, \mathrm{P}_{\mathrm{y}}^{825}$ & ${ }^{817} \mathrm{GPOGPM}_{\mathrm{ox}} \mathrm{GPP}_{\mathrm{y}} \mathrm{GLAGPOGESGR}$ \\
\hline 1848.8545 & +16 & 41 & $\mathrm{M}_{\mathrm{ox}}{ }^{822}$ & ${ }^{817} \mathrm{GPOGPM}_{\mathrm{ox}} \mathrm{GPOGLAGPOGESGR}$ \\
\hline 2105.0006 & -16 & 66 & $\mathbf{P}_{\mathrm{y}}{ }^{771}$ & ${ }^{757}$ GSOGADGPAGAOGTP $_{\mathrm{y}}$ GPQGIAGQR \\
\hline 2120.9955 & & 58 & & ${ }^{757}$ GSOGADGPAGAOGTOGPQGIAGQR \\
\hline 2497.2066 & -16 & 81 & $\mathbf{P}_{\mathrm{y}}{ }^{876}$ & ${ }^{856}$ GDRGETGPAGPOGAOGAOGAP GPVGPAGK \\
\hline 2513.2015 & & 109 & & ${ }^{856} \mathrm{GDRGETGPAGPOGAOGAOGAOGPVGPAGK}$ \\
\hline 2703.2394 & -16 & 63 & $\mathbf{P}_{\mathrm{y}}{ }^{645}$ & ${ }^{6{ }^{19} \mathrm{GAOGDRGEOGPOGPAGFAGPOGADGQP} \mathrm{y} G \mathrm{~K}}$ \\
\hline 2149.9785 & & 73 & & $\begin{array}{l}{ }^{625} \mathrm{GEOGPOGPAGFAGPOGADGQOGAK} \\
\end{array}$ \\
\hline \multicolumn{5}{|l|}{$\alpha 2$ chain } \\
\hline 1168.4978 & -16 & 61 & $\mathrm{P}_{\mathrm{y}}^{840}$ & ${ }^{837}$ DGNPy $_{y}$ GNDGPOGR \\
\hline \multicolumn{5}{|c|}{ B. Human type III collagen } \\
\hline$\alpha 1$ chain & & & & \\
\hline
\end{tabular}




\begin{tabular}{|c|c|c|c|c|}
\hline 949.5102 & -16 & 45 & $\mathbf{P}_{\mathbf{y}}{ }^{981}$ & ${ }^{973}$ GPVGPSGPP $\mathbf{y}$ GK \\
\hline 965.5051 & & 44 & & ${ }^{973}$ GPVGPSGPOGK \\
\hline 1138.5674 & & 65 & & ${ }^{790}$ GLAGPOGMOGPR \\
\hline 1154.5623 & +16 & 41 & $\mathrm{M}_{\mathrm{ox}}{ }^{797}$ & ${ }^{790} \mathrm{GLAGPOGM}_{\mathrm{ox}} \mathrm{OGPR}$ \\
\hline 1203.5827 & & 57 & & ${ }^{406}$ GQOGVMGFOGPK \\
\hline 1219.5776 & +16 & 42 & $O_{x}^{416}$ & ${ }^{406}$ GQOGVMGFOG $O_{x} K$ \\
\hline 1514.7346 & -16 & 50 & $\mathrm{P}_{\mathrm{y}} 990$ & ${ }^{984}$ DGTSGHP GPIGPOGPR \\
\hline 1530.7295 & & 57 & & ${ }^{984}$ DGTSGHOGPIGPOGPR \\
\hline 1670.7989 & & 42 & $\mathrm{P}_{\mathrm{y}}^{240}, \mathrm{M}_{\mathrm{ox}}{ }^{243}$ & ${ }^{229} \mathrm{GEMGPAGIOGAP}_{\mathrm{y}} \mathrm{GLM}_{\mathrm{ox}} \mathrm{GAR}$ \\
\hline 2088.0832 & -16 & 94 & $\mathbf{P}_{\mathbf{y}}{ }^{777}$ & ${ }^{766}$ GSOGAQGPOGAP $\mathbf{y}_{\mathrm{y}}$ GPLGIAGITGAR \\
\hline 2104.0782 & & 137 & & ${ }^{766}$ GSOGAQGPOGAOGPLGIAGITGAR \\
\hline 2283.1000 & & 79 & & ${ }^{667}$ GEGGPOGVAGPOGGSGPAGPOGPQGVK \\
\hline 2299.0949 & +16 & 106 & $O_{x}{ }^{686}$ or $O_{x}{ }^{689}$ or $K_{o x}{ }^{693}$ & ${ }^{667}$ GEGGPOGVAGPOGGSGPAGPOGPQGVK \\
\hline 2950.4653 & & 82 & & ${ }^{595}$ GPTGPIGPOGPAGQOGDKGEGGAOGLOGIAGPR \\
\hline 2966.4603 & +16 & 58 & $O_{x}^{605}$ & ${ }^{595}$ GPTGPIGPOG $\boldsymbol{O}_{x}$ AGQOGD $K$ GEGGAOGLOGIAGPR \\
\hline
\end{tabular}

465 a: The mass of the single charged ion used to identify each peptide. The sequencing results of most of the peptides are based on the fragmentation of the double charged species (see below).

467 b: The mass differences compared to the 'theoretical' assuming all Pro in the Y positions are hydroxylated.

468 c: The score of Mascot search engine (see Material and Methods).

469 d: Unexpected hydroxylation of X-Pro and unhydroxylated Y-Pro are shown as $\mathrm{O}_{\mathrm{x}}$ and $\mathrm{P}_{\mathrm{y}}$; those observed in more 470 than one sequencing effort are in bold; those with uncertainties are shown in italic (see text).

474 (peptide mass 2966.6403). The peptide with mass 2966.4603 contains an internal Lys ${ }^{612}$, the +16

475 mass was tentatively assigned to the hydroxylation of $\mathrm{O}_{\mathrm{x}}{ }^{605}$ for lacking complete fragmentation

476 between $\mathrm{O}_{\mathrm{x}}{ }^{605}$ and $\mathrm{Lys}^{612}$. The peptide 406-417 (mass 1219.5776) carries the Met ${ }^{411}$, which can

477 potentially be oxidized with a mass increase of 16; the fragmentation data has ruled out this 
478 possibility. Overall five $\mathrm{P}_{\mathrm{y}}$ residues were detected in $\alpha 1$ (III) samples, and the $\mathrm{P}_{\mathrm{y}}{ }^{981}$ was seen with 479 a very strong signal in every sequencing outcome.

In summary, the MS/MS sequencing results are mapped out on the sequences of the five

$481 \alpha$-chains arranged in $D$-periodicity in Fig. 3. Using the rather stringent sequencing criteria

482 outlined in Materials and Methods the sequence coverage is about 35\% for type III collagen and

483 around $56 \%$ for the $\alpha_{1}(\mathrm{I})$ and $46 \%$ for the $\alpha_{2}(\mathrm{I})$ chains of human type I collagen, and about $62 \%$

484 and $67 \%$ for $\alpha_{1}(\mathrm{I})$ and $\alpha_{2}(\mathrm{I})$ chains, respectively, of rat tail tendon type I collagen combining

485 both samples. Some observations of the $\mathrm{O}_{\mathrm{x}}$ are consistent between the two different rat tail

486 tendon samples, such as those in the HVRs; the others appeared sporadic. Most of the over-

487 hydroxylations seen in the rat tail tendon type I collagen are not present in human placental type

488 I collagen. The consistent observations between the human type I collagen and that of the rat tail

489 tendon include the Hyp ${ }^{986}$ of the $\alpha 1$ chain and $\mathrm{P}_{\mathrm{y}}$ resides at positions 771 and 876 of the $\alpha 1$ (I)

490 chain.

491

492

493

494

495

\section{Discussion}

By carrying out this study of the selected collagen samples we are hoping to gain a better understanding of the variations in the hydroxylation of fibrillar collagen in MS studies. Because

of the high sensitivity of the MS and MS/MS approach, observing unusual hydroxylation of collagen proves to be a common event. Using a standard protein mass-spec sequencing technique we have detected unusual hydroxylation at several levels in rat type I collagen, human type I collagen and human type III collagen. The variations of the hydroxylation were supported by the 501 spectrometry data for both the fragmented ions and the overall mass of the tryptic peptides. The 
over-hydroxylation was largely attributed to the hydroxylation of Pro in the X-positions, which is especially prevalent in both the $\alpha 1(\mathrm{I})$ and the $\alpha 2(\mathrm{I})$ chains of the type I collagen of rat tail tendon.

504 The heterogeneity in the hydroxylation of human collagen type I and type III is much lower, 505 reflecting the variations in enzyme selectivity of the hydroxylase among different species and/or 506 tissues. As expected, most of the hydroxylated proline residues in the X-position are detected as 507 a mixture; some may be present at a relatively low level, while others, as those in the highly 508 variable regions (HRVs), are more prevalent and representative.

510 variations as shown in Tables 1-3; detections of about half of the $\mathrm{O}_{\mathrm{x}}$ and $\mathrm{P}_{\mathrm{y}}$ residues are seen in 511 multiple sequencing efforts (in boldface), while that of the others are less reproducible. In fact,

512 the variations in the sequencing results of the two very different rat tail tendon samples are not in 513 any way more substantial than that of the repeated sequencings of the same collagen samples.

514 Such varied outcomes reflected the complex and unpredictable nature of the ionization process

515 of MS and sample handling (52). Each sequencing outcome often represents no more than a 516 single sampling of a population consisting of heterogeneous modifications. The unpredictable

517 ionization process is one of the major concerns for quantitative estimation of the populations of 518 the sequenced peptides using MS/MS, especially when the sample is heterogeneous and the 519 scope of the PTMs of the protein is not fully characterized. Sequence coverage will also affect 520 the detection of PTMs, and this may be the reason that the canonical $3 \mathrm{Hyp}^{986}$ of the $\alpha 1(\mathrm{I})$ chain 521 was detected only once among multiple sequencing attempts of samples from human placenta 522 and from srtt; this tryptic peptide containing position 986 was not sequenced at all in the 523 commercial rat tail sample. Protocols using multiple proteases will result in a better sequence 524 coverage, especially in cases like type III collagen where the tryptic peptides are often either too 
525 large or too small for reliable MS/MS results. On the other hand, despite the low sequence

526 coverage, several unusual hydroxylations were observed rather consistently (Table 3, Fig 3). The

527 observations of the $\mathrm{O}_{\mathrm{x}}$ residues, in the highly variable regions of the rat tail tendon type I

528 collagen is quite robust and consistent even among samples prepared from different sources. collagen in rat tail tendon is in keeping with the unusually high 3Hyp content of this collagen (53). The amino acid composition analysis estimated three to four $3 \mathrm{Hyp}$ in each of the $\alpha 1$ (I) and the $\alpha 2(\mathrm{I})$ chains of the rat tail tendon type I collagen, compared to only one 3 Hyp, the Hyp ${ }^{986}$, in

533 the rat $\alpha 1(\mathrm{I})$ chain of type I collagen from bones or skin. The $\mathrm{O}_{\mathrm{x}}{ }^{707}, \mathrm{O}_{\mathrm{x}}{ }^{716}$ and $\mathrm{O}_{\mathrm{x}}{ }^{719}$ of the $\alpha 2$ (I)

534 chains were subsequently identified as 3Hyp by N-terminal sequencing (4). The C-HVR also

535 includes the location of the 'class-2' $3 \mathrm{Hyp}^{707}$ in the human $\alpha 2$ (I) chain observed previously (9).

536 Unfortunately this segment of the human $\alpha 2(\mathrm{I})$ chain was not sequenced in our study despite

537 repeated attempts; the same region in the human $\alpha 1(\mathrm{I})$, which has the same amino acid sequence

538 as that in the $\alpha 2(\mathrm{I})$ chain, was sequenced, but no X-Hyp was found. The over-hydroxylation in

539 the N-HVR of residue 238-252 of rat tendon $\alpha 1(\mathrm{I})$ has never been reported before. Multiple $\mathrm{O}_{\mathrm{x}}$

540 residues in this region in both samples of the rat tendon collagen were observed with

541 reproducible results. Interestingly, the amino acid sequences of the two highly variable regions

542 share limited homology; they are also rather different from the sequence surrounding the $3 \mathrm{Hyp}^{986}$.

543 The two $\mathrm{O}_{\mathrm{x}}$ residues of the N-HVR, $\mathrm{O}_{\mathrm{x}}{ }^{239}$ and $\mathrm{O}_{\mathrm{x}}{ }^{245}$, appeared in the peptide triad of $\mathrm{GO}_{\mathrm{x}} \mathrm{S}$, while

544 the $\mathrm{O}_{\mathrm{x}}{ }^{707}$ and $\mathrm{O}_{\mathrm{x}}{ }^{716}$ of C-HVR in both $\alpha 1(\mathrm{I})$ and $\alpha 2(\mathrm{I})$ chains are in the more common $\mathrm{GO}_{\mathrm{x}} \mathrm{O}$

545 moiety; but the $\mathrm{O}_{\mathrm{x}}{ }^{722}$ of the $\alpha \mathrm{l}(\mathrm{I})$ chain is in $\mathrm{GO}_{\mathrm{x}} \mathrm{V}$ triplet. The GOA and GOS are two moieties 546 identified for X-Hyp of type V collagen (10). It is also worth noting that, similar to the 3Hyp 
547 residues identified by Eyre and colleagues, the two HVRs of rat tail tendon type I collagen are

548 located exactly a $2 D$-period apart (Fig. 3), although the significance of it remains to be evaluated

549 (9). No further effort was made to confirm the 3Hyp identity of the identified $\mathrm{O}_{\mathrm{x}}$ in this study.

550 While most of the newly identified X-Hyp residues have been confirmed to be $3 \mathrm{Hyp}$, at least in 551 one occasion an X-Hyp was later confirmed to be a 4R-Hyp (54).

554 of the detected Y-Pro residues are present as a mixed population having varied occupancies.

555 Combining all the five $\alpha$ chains, the $\mathrm{P}_{\mathrm{y}}$ residues were observed in 29 peptides. It is tempting to

556 postulate the region of residues 273-302 of rat tail tendon type I collagen, where up to $5 \mathrm{P}_{\mathrm{y}}$

557 residues were found within a short stretch of 38-residues, to have unique conformational

558 dynamics, since a Pro in the Y-position is known to significantly destabilize the triple helix

559 compared to a Hyp (55). The real impact will, of course, depend on the percent of occupancy in

560 these sites.

While incomplete hydroxylation has been known for some time, the site-specific data and

562 the sequence motif of the missed-hydroxylations have not been reported before. The sequence

563 information of the $\mathrm{P}_{\mathrm{y}}$ residues may relate to the substrate selectivity of the prolyl-4-hydroxylase

564 (C-P4H). Studies using short peptides established that the enzyme recognizes Pro-Gly-Xaa

565 triplets during hydroxylation, where the Pro is the residue to be hydroxylated, and the selection

566 of the Pro in a Y-position is affected by the conformation around the -Gly-Xaa residues (56-58).

567 The hydroxylation takes place on the nascent polypeptide chains before the formation of the

568 triple helix. Despite the higher than normal content of the Pro residues, the unfolded $\alpha$-chains of

569 collagen are not known to assume any well-defined conformation, although isolated segments 
may temporarily adapt to polyproline II (PP II) like or $\beta$-turn like $\phi$ and $\varphi$ angles. Specifically,

571 the type II $\beta$-turn bent between the -Gly-Xaa was considered to favor the binding of C-P4H and

572 thus, the hydroxylation of the Pro proceeding the Gly; while the PPII conformation in -Gly-Xaa

573 was considered inhibitory $(57,58)$. Residues Ala, Leu, Ile, and Phe in the position of Xaa were

574 found to favor a $\beta$-turn around the Gly, and a Pro favors a PPII $\phi$ and $\varphi$ angles (58). Our finding

575 here appears to reflect this conformational preference of C-P4H in vivo. If we consider the $\mathrm{P}_{\mathrm{y}}$ as

576 a miss of the C-P4H in selecting a Pro in a Y-position for hydroxylation, the hydroxylation

577 action appears to be particularly slippery in the sequence context of Pro-Gly-Pro. Nineteen out of

578 the $36 \mathrm{P}_{\mathrm{y}}$ residues identified in the $5 \alpha$ chains are in the $\mathrm{P}_{\mathrm{y}}$-Gly-Pro moiety. On the other hand,

579 this high occurrence of $\mathrm{P}_{\mathrm{y}}$-Gly-Pro moiety may simply reflect the higher frequencies of genomic

580 sequence pro-gly-pro in fibrillar collagen. The other frequent misses include $\mathrm{P}_{\mathrm{y}}$ in Pro-Gly-Glu

581 (5/33), Pro-Gly-Ser (4/30) triplets, and Pro-Gly-Leu (3/33) triplet. Among the identified $\mathrm{P}_{\mathrm{y}}$

582 residues, the $\mathrm{P}_{\mathrm{y}}{ }^{771}$ of $\alpha 1(\mathrm{I})$ in a $\mathrm{P}_{\mathrm{y}}$-Gly-Pro moiety is the only one that is identified in both human

583 and the two rat tail tendon samples. The $\mathrm{P}_{\mathrm{y}}{ }^{876}$, also in $\mathrm{P}_{\mathrm{y}}$-Gly-Pro moiety, of $\alpha 1(\mathrm{I})$ was detected

584 in human and the commercial sample of rat tail tendon, but not in the srtt sample. There also

585 appears to be an overrepresentation of $\mathrm{P}_{\mathrm{y}}$ residues in a $\mathrm{GEP}_{\mathrm{y}}$ tripeptide in rat type I collagen: 8

586 out of the 23 identified $\mathrm{P}_{\mathrm{y}}$ residues are in a GEP moiety. It is not clear if the Glu preceding the

587 Pro in the $\mathrm{Y}$-position affects the selectivity of C-P4H in rat tail tendon. Other more common

588 sequence motifs for $\mathrm{P}_{\mathrm{y}}$ are $\mathrm{GAP}_{\mathrm{y}}, \mathrm{GPP}_{\mathrm{y}}$ and $\mathrm{GSP}_{\mathrm{y}}$. It is also unclear if the missed hydroxylation

589 of these residues has any functional roles for collagen. 
The high sensitivity of MS/MS sequencing has revealed a subpopulation of collagen that

593 bares unexpected hydroxylated Pro in the X-positions, and unhydroxylated Pro in the Y-

594 positions. The detection of X-Hyp and the Y-Pro by mass-spec sequencing is impacted by both

595 the tissue/organism dependent variations of the Pro-hydroxylation reaction and the statistic

596 nature of the technique. The detection of some modifications, however, is rather robust and can

597 be used as a biomarker for general applications using MS/MS. A more thorough understanding

598 of the dynamics of the specific PTM of 3-Hyp in the X-position and its role in epigenetic

599 regulation will require a knowledge base that is broad enough to reflect the statistical nature of

600 both the variations of the PTMs in different tissues and organisms, and the reproducibility of

601 their detections by MS/MS.

\section{Acknowledgements}

607 The authors are indebted to Dr. Sergey Leikin, and Dr. Elena N. Makareeva for their help 608 preparing rat tail collagen, Dr. Milica Tesic Marks for some sequencing and data processing, Dr.

609 Henrik Molina for Discoverer software assistance and the overall guidance on mass-spec

610 technology. We would also like to thank Drs. Rebecca Strawn, James San Antonio and late Adel

611 Bosky for critical reading of this and a previous version of the manuscript.

\section{References}


615 1. Buckley M, Collins M, Thomas-Oates J, Wilson JC. Species identification by analysis of 616 bone collagen using matrix-assisted laser desorption/ionisation time-of-flight mass spectrometry. 617 Rapid communications in mass spectrometry : RCM. 2009;23(23):3843-54.

618 2. van Huizen NA, Ijzermans JNM, Burgers PC, Luider TM. Collagen analysis with mass

619 spectrometry. Mass spectrometry reviews. 2020;39(4):309-35.

6203 3. Henkel W, Dreisewerd K. Cyanogen bromide peptides of the fibrillar collagens I, III, and

$621 \mathrm{~V}$ and their mass spectrometric characterization: detection of linear peptides, peptide

622 glycosylation, and cross-linking peptides involved in formation of homo- and heterotypic fibrils.

623 Journal of proteome research. 2007;6(11):4269-89.

624 4. Taga Y, Kusubata M, Ogawa-Goto K, Hattori S. Developmental Stage-dependent

625 Regulation of Prolyl 3-Hydroxylation in Tendon Type I Collagen. J Biol Chem.

626 2016;291(2):837-47.

627 5. Eyre DR, Paz MA, Gallop PM. Cross-linking in collagen and elastin. Annual review of

628 biochemistry. 1984;53:717-48.

629 6. Eyre DR, Weis M, Hudson DM, Wu JJ, Kim L. A novel 3-hydroxyproline (3Hyp)-rich

630 motif marks the triple-helical $\mathrm{C}$ terminus of tendon type I collagen. The Journal of biological

631 chemistry. 2011;286(10):7732-6.

632 7. Eyre DR, Wu J-J. Collagen Cross-Links. Top Curr Chem. 2005;247:207-29.

633 8. Fernandes RJ, Farnand AW, Traeger GR, Weis MA, Eyre DR. A role for prolyl 3-

634 hydroxylase 2 in post-translational modification of fibril-forming collagens. The Journal of

635 biological chemistry. 2011;286(35):30662-9.

636 9. Weis MA, Hudson DM, Kim L, Scott M, Wu JJ, Eyre DR. Location of 3-hydroxyproline

637 residues in collagen types I, II, III, and V/XI implies a role in fibril supramolecular assembly.

638 The Journal of biological chemistry. 2010;285(4):2580-90.

639 10. Yang C, Park AC, Davis NA, Russell JD, Kim B, Brand DD, et al. Comprehensive mass

640 spectrometric mapping of the hydroxylated amino acid residues of the alpha1(V) collagen chain.

641 The Journal of biological chemistry. 2012;287(48):40598-610.

642 11. Engel J, Bachinger HP. Structure, stability and folding of the collagen triple helix. Top

643 Curr Chem. 2005;247:7-33.

644 12. Birk DE, Bruckner P. Collagen suprastructures. Top Curr Chem. 2005;247:185-205.

645 13. Cabral WA, Chang W, Barnes AM, Weis M, Scott MA, Leikin S, et al. Prolyl 3-

646 hydroxylase 1 deficiency causes a recessive metabolic bone disorder resembling lethal/severe

647 osteogenesis imperfecta. Nature genetics. 2007;39(3):359-65.

648 14. Marini JC, Forlino A, Bächinger HP, Bishop NJ, Byers PH, Paepe A, et al. Osteogenesis 649 imperfecta. Nature reviews Disease primers. 2017;3:17052.

650 15. Maity PP, Dutta D, Ganguly S, Kapat K, Dixit K, Chowdhury AR, et al. Isolation and

651 mass spectrometry based hydroxyproline mapping of type II collagen derived from Capra hircus

652 ear cartilage. Communications biology. 2019;2:146.

653 16. Taga Y, Kusubata M, Ogawa-Goto K, Hattori S. Stable isotope-labeled collagen: a novel

654 and versatile tool for quantitative collagen analyses using mass spectrometry. Journal of

655 proteome research. 2014;13(8):3671-8.

656 17. Fang M, Yuan J, Peng C, Li Y. Collagen as a double-edged sword in tumor progression.

657 Tumour biology : the journal of the International Society for Oncodevelopmental Biology and

658 Medicine. 2014;35(4):2871-82. 
18. Zhen EY, Brittain IJ, Laska DA, Mitchell PG, Sumer EU, Karsdal MA, et al.

660 Characterization of metalloprotease cleavage products of human articular cartilage. Arthritis

661 Rheum. 2008;58(8):2420-31.

662 19. Szpak P. Fish bone chemistry and ultrastructure: implications for taphonomy and stable

663 isotope analysis. Journal of Archaeological Science. 2011;38(12):3358-72.

664 20. Kielty CM, Hopkinson I, Grant ME. The Collagen Family: Structure, Assembly, and 665 Organization in the Extracellular Matrix. in Royce, P M, and Steinmann, B (Eds), Connective 666 Tissue and Its Heritable Disorders, pp 103-147, Wiley-Liss, New York. 1993:103-47.

667 21. Piez KA. Primary Structure. in Ramachandran, G N and Reddi, A H (Eds), Biochemistry 668 of Collagens, Plenum Press, New York and London1976. p. 1-44.

669 22. Bornstein P, Piez KA. The nature of the intramolecular cross-links in collagen. The 670 separation and characterization of peptides from the cross-link region of rat skin collagen.

671 Biochemistry. 1966;5(11):3460-73.

672 23. Kivirikko KI, Ryhanen L, Anttinen H, Bornstein P, Prockop DJ. Further hydroxylation of 673 lysyl residues in collagen by protocollagen lysyl hydroxylase in vitro. Biochemistry.

674 1973;12(24):4966-71.

675 24. Ogle JD, Arlinghaus RB, Lgan MA. 3-Hydroxyproline, a new amino acid of collagen.

676 The Journal of biological chemistry. 1962;237:3667-73.

677 25. Prockop DJ, Berg RA, Kivirikko KI, Uitto J. Intracellular Steps in the Biosynthesis of

678 Collagen. in Ramachandran, G N and Reddi, A H (Eds), Biochemistry of Collagens, Plenum

679 Press, New York and London. 1976:163 - 274.

680 26. Privalov PL, Tictopulo EI, Tischenko VM. Stability and Mobility of the Collagen

681 Structure. J Mol Biol. 1979;127:203-16.

682 27. Holmes DF, Kadler KE. The 10+4 microfibril structure of thin cartilage fibrils. Proc Natl 683 Acad Sci U S A. 2006;103(46):17249-54.

684 28. Ruggiero F, Exposito J, Bournat P, Gruber V, Perret S, Comte J, et al. Triple Helix Assembly and Processing of Human Collagen Produced in Transgenic Tobacco Plants. FEBS Letters. 2000;469:132-6.

688 primary structure of collagen for the origins of molecular packing. J Mol Biol. 1973;79(1):137-

68948.

690 30. Berg RA, Prockop DJ. The thermal transition of a non-hydroxylated form of collagen.

691 Evidence for a role for hydroxyproline in stabilizing the triple-helix of collagen. Biochem

692 Biophys Res Commun. 1973;52(1):115-20.

693 31. Sakakibara S, Inouye K, Shudo K, Kishida Y, Kobayashi Y, Prockop DJ. Synthesis of 694 (Pro-Hyp-Gly) n of defined molecular weights. Evidence for the stabilization of collagen triple helix by hydroxypyroline. Biochim Biophys Acta. 1973;303(1):198-202.

696 32. Engel J, Chen HT, Prockop DJ, Klump H. The triple helix in equilibrium with coil 697 conversion of collagen-like polytripeptides in aqueous and nonaqueous solvents. Comparison of 698 the thermodynamic parameters and the binding of water to (L-Pro-L-Pro-Gly)n and (L-Pro-L699 Hyp-Gly)n. Biopolymers. 1977;16(3):601-22.

700 33. Persikov AV, Ramshaw JAM, Kirkpatrick A, Brodsky B. Amino Acid Propensities for 701 the Collagen Triple-Helix. Biochemistry. 2000;39:14960-7.

702 34. Burjanadze TV. New analysis of the phylogenetic change of collagen thermostability. 703 Biopolymers. 2000;53(6):523-8. 
35. Saito M, Marumo K. Effects of Collagen Crosslinking on Bone Material Properties in Health and Disease. Calcified tissue international. 2015;97(3):242-61.

36. Heikkinen J, Risteli M, Wang C, Latvala J, Rossi M, Valtavaara M, et al. Lysyl Hydroxylase 3 Is a Multifunctional Protein Possessing Collagen Glucosyltransferase Activity*. Journal of Biological Chemistry. 2000;275(46):36158-63.

37. Sricholpech M, Perdivara I, Nagaoka H, Yokoyama M, Tomer KB, Yamauchi M. Lysyl Hydroxylase 3 Glucosylates Galactosylhydroxylysine Residues in Type I Collagen in Osteoblast Culture*. Journal of Biological Chemistry. 2011;286(11):8846-56.

38. Valli M, Barnes AM, Gallanti A, Cabral WA, Viglio S, Weis MA, et al. Deficiency of CRTAP in non-lethal recessive osteogenesis imperfecta reduces collagen deposition into matrix. Clinical genetics. 2012;82(5):453-9.

39. Marini JC, Cabral WA, Barnes AM, Chang W. Components of the collagen prolyl 3hydroxylation complex are crucial for normal bone development. Cell cycle. 2007;6(14):1675-81. 40. Lothrop AP, Torres MP, Fuchs SM. Deciphering post-translational modification codes. FEBS letters. 2013;587(8):1247-57.

41. Chait BT. Mass spectrometry in the postgenomic era. Annu Rev Biochem. 2011;80:23946.

42. Lange V, Picotti P, Domon B, Aebersold R. Selected reaction monitoring for quantitative proteomics: a tutorial. Molecular systems biology. 2008;4:222.

43. Hunt DF, Yates JR, 3rd, Shabanowitz J, Winston S, Hauer CR. Protein sequencing by tandem mass spectrometry. Proceedings of the National Academy of Sciences of the United States of America. 1986;83(17):6233-7.

44. Huang Y, Triscari JM, Pasa-Tolic L, Anderson GA, Lipton MS, Smith RD, et al. Dissociation behavior of doubly-charged tryptic peptides: correlation of gas-phase cleavage abundance with ramachandran plots. Journal of the American Chemical Society. 2004;126(10):3034-5.

45. Vaisar T, Urban J. Probing the proline effect in CID of protonated peptides. Journal of mass spectrometry : JMS. 1996;31(10):1185-7.

46. Makareeva E, Cabral WA, Marini JC, Leikin S. Molecular mechanism of alpha 1(I)osteogenesis imperfecta/Ehlers-Danlos syndrome: unfolding of an N-anchor domain at the Nterminal end of the type I collagen triple helix. J Biol Chem. 2006;281(10):6463-70.

47. Bern M, Saladino J, Sharp JS. Conversion of methionine into homocysteic acid in heavily oxidized proteomics samples. Rapid communications in mass spectrometry : RCM. 2010;24(6):768-72.

48. Molony MS, Quan C, Mulkerrin MG, Harris RJ. Hydroxylation of Lys residues reduces their susceptibility to digestion by trypsin and lysyl endopeptidase. Analytical biochemistry. 1998;258(1):136-7.

49. Di Lullo GA, Sweeney SM, Korkko J, Ala-Kokko L, San Antonio JD. Mapping the ligand-binding sites and disease-associated mutations on the most abundant protein in the human, type I collagen. J Biol Chem. 2002;277(6):4223-31.

50. Guan Z, Yates NA, Bakhtiar R. Detection and characterization of methionine oxidation in peptides by collision-induced dissociation and electron capture dissociation. J Am Soc Mass Spectrom. 2003;14(6):605-13.

51. Houde D, Kauppinen P, Mhatre R, Lyubarskaya Y. Determination of protein oxidation by mass spectrometry and method transfer to quality control. Journal of chromatography A. 2006;1123(2):189-98. 
750 52. Cox JT, Marginean I, Smith RD, Tang K. On the ionization and ion transmission 751 efficiencies of different ESI-MS interfaces. J Am Soc Mass Spectrom. 2015;26(1):55-62.

752 53. Piez KA, Eigner EA, Lewis MS. The Chromatographic Separation and Amino Acid

753 Composition of the Subunits of Several Collagens*. Biochemistry. 1963;2((1)):58-66.

754 54. van Huizen NA, Burgers PC, Saintmont F, Brocorens P, Gerbaux P, Stingl C, et al.

755 Identification of 4-Hydroxyproline at the Xaa Position in Collagen by Mass Spectrometry.

756 Journal of proteome research. 2019;18(5):2045-51.

757 55. Burjanadze TV, Bezhitadze MO. Presence of a thermostable domain in the helical part of

758 the type I collagen molecule and its role in the mechanism of triple helix folding. Biopolymers.

759 1992;32(8):951-6.

760 56. Bhatnagar RS, Rapaka RS. Synthetic Polypeptide Models of Collagen: Synthesis and

761 Applications. in Ramachandran, G N and Reddi, A H (Eds), Biochemistry of Collagens, Plenum

762 Press, New York and London. 1976:479 - 523.

763 57. Prockop DJ, Kivirikko KI. Effect of polymer size on the inhibition of protocollagen

764 proline hydroxylase by polyproline II. The Journal of biological chemistry. 1969;244(18):4838-

76542.

766 58. Brahmachari SK, Ananthanarayanan VS. Beta-turns in nascent procollagen are sites of

767 posttranslational enzymatic hydroxylation of proline. Proceedings of the National Academy of

768 Sciences of the United States of America. 1979;76(10):5119-23.

769

770 Supporting Information

771 S1: The Complete Sequencing Results 
Figure 1

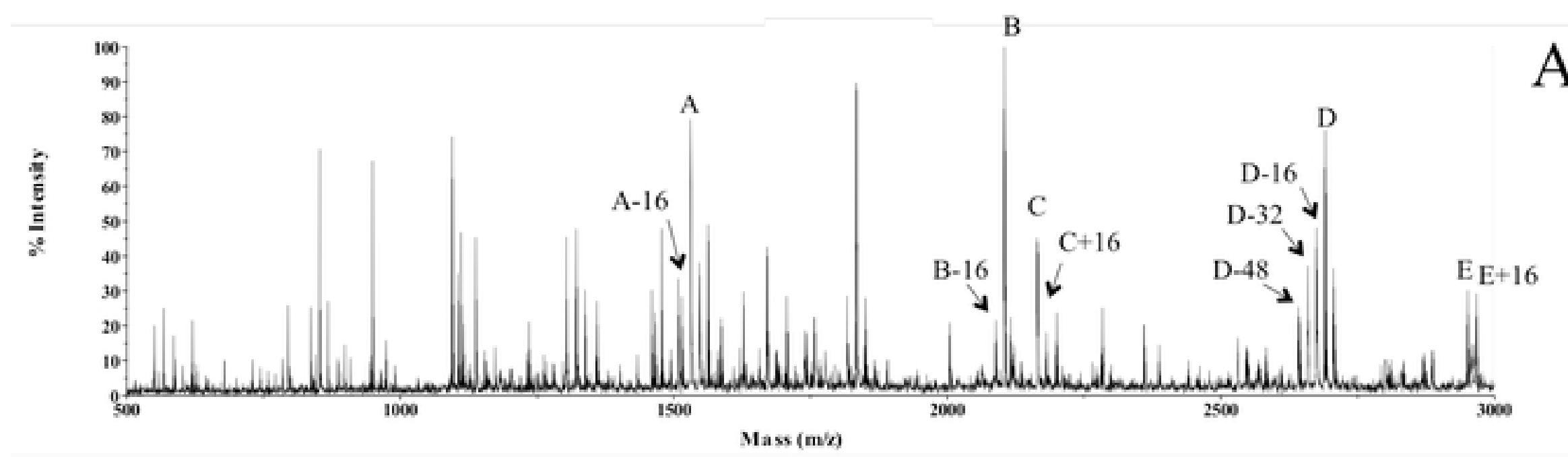

A

bioRxiv preprint doi: https://doi.org/10.1101/2021.04.12.439427; this version posted April 12, 2021. The copyright holder for this preprint (which

was not certified by peer review) is the author/funder, who has granted bioRxiv a license to display the preprint in perpetuity. It is made

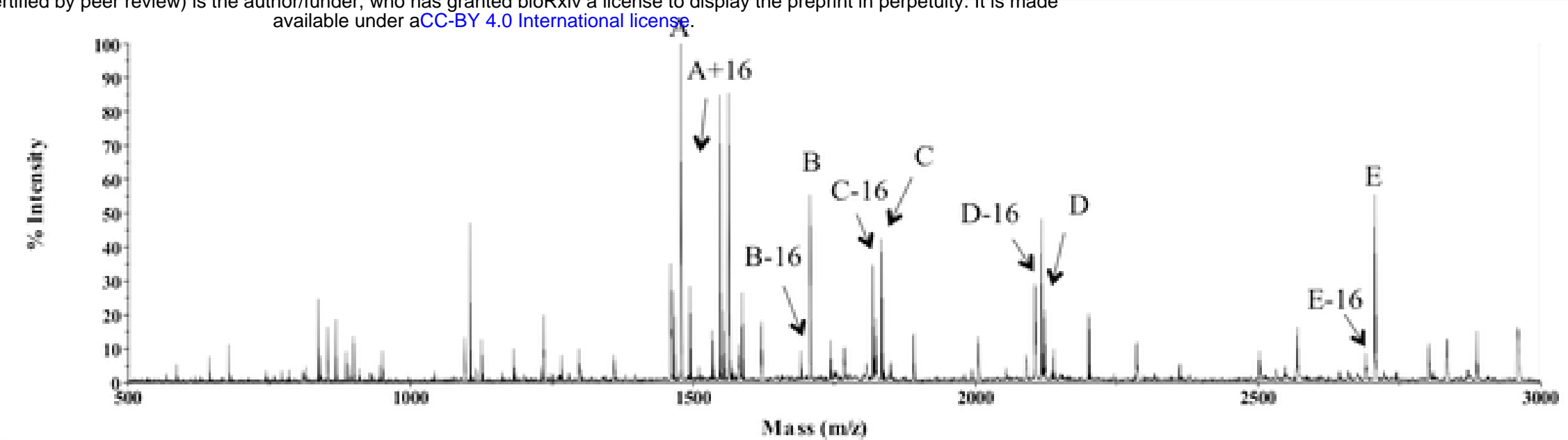

B

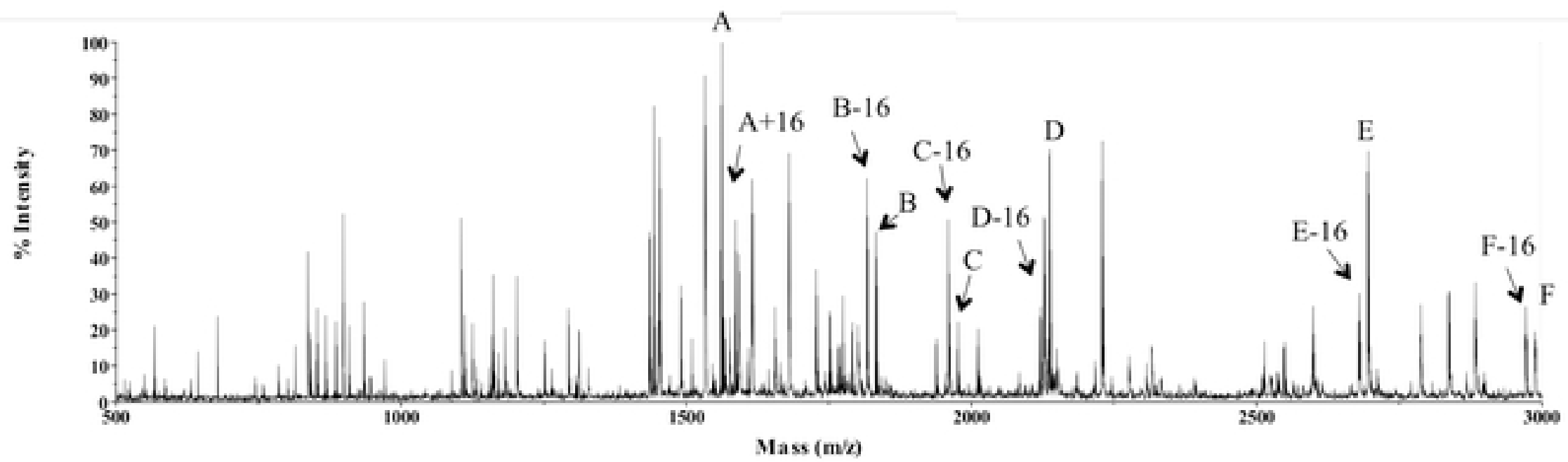

Figure 1 


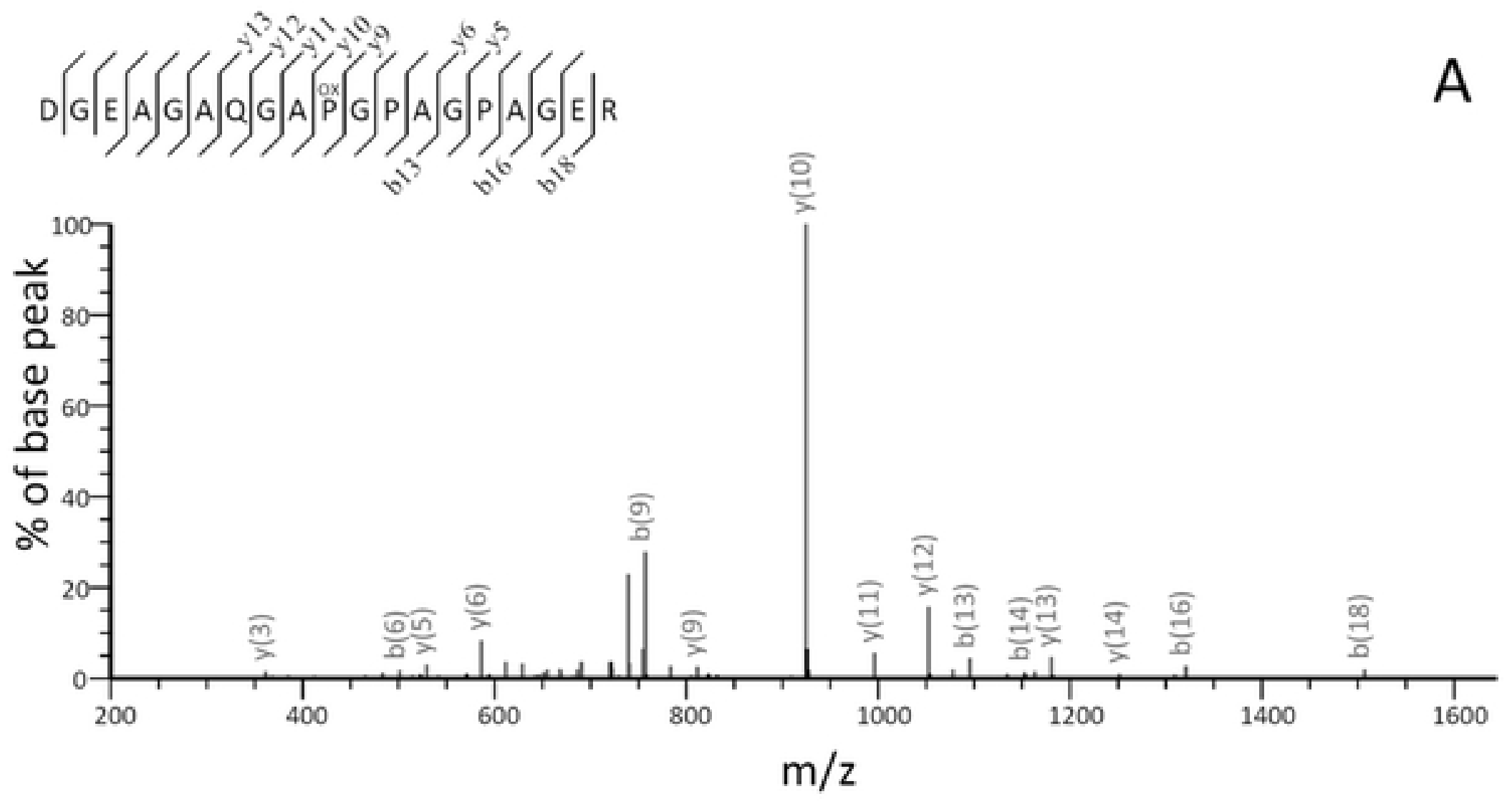

bioRxiv preprint doi: https://doi.org/10.1101/2021.04.12,43942 was not certified by peer reviewy is the authorffunder/who has granted bioRxiv a license to display the preprint in perpetuity. It is made

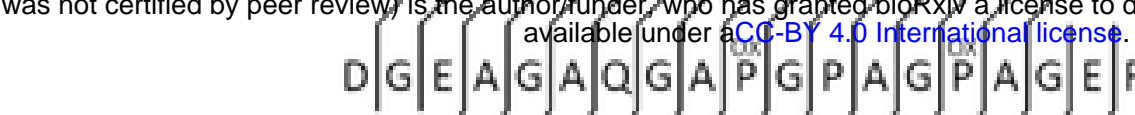

B
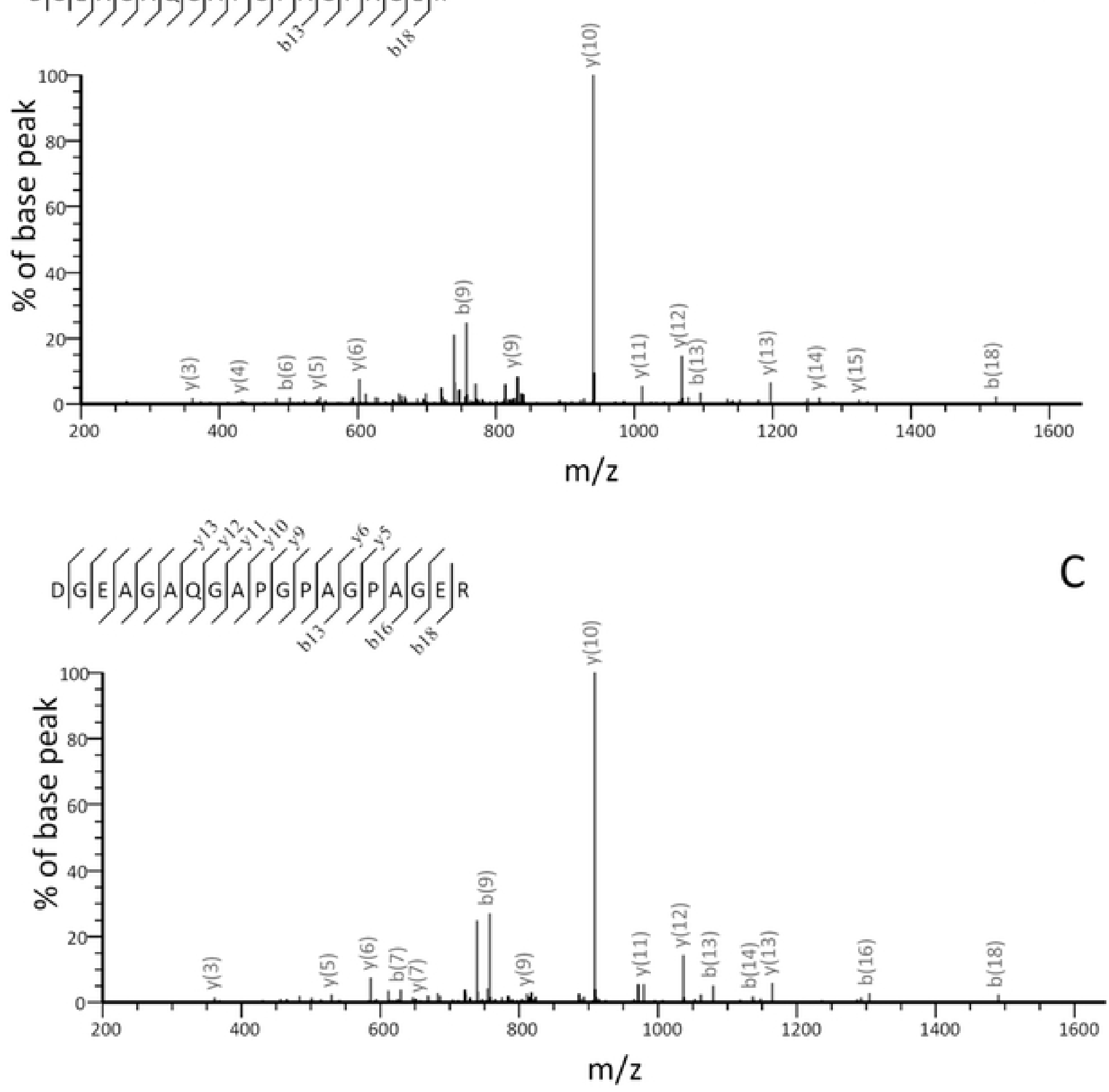

Figure 2 
Figure 3

The sequence of collagen $\boldsymbol{\alpha}$-chains in D-periodicity

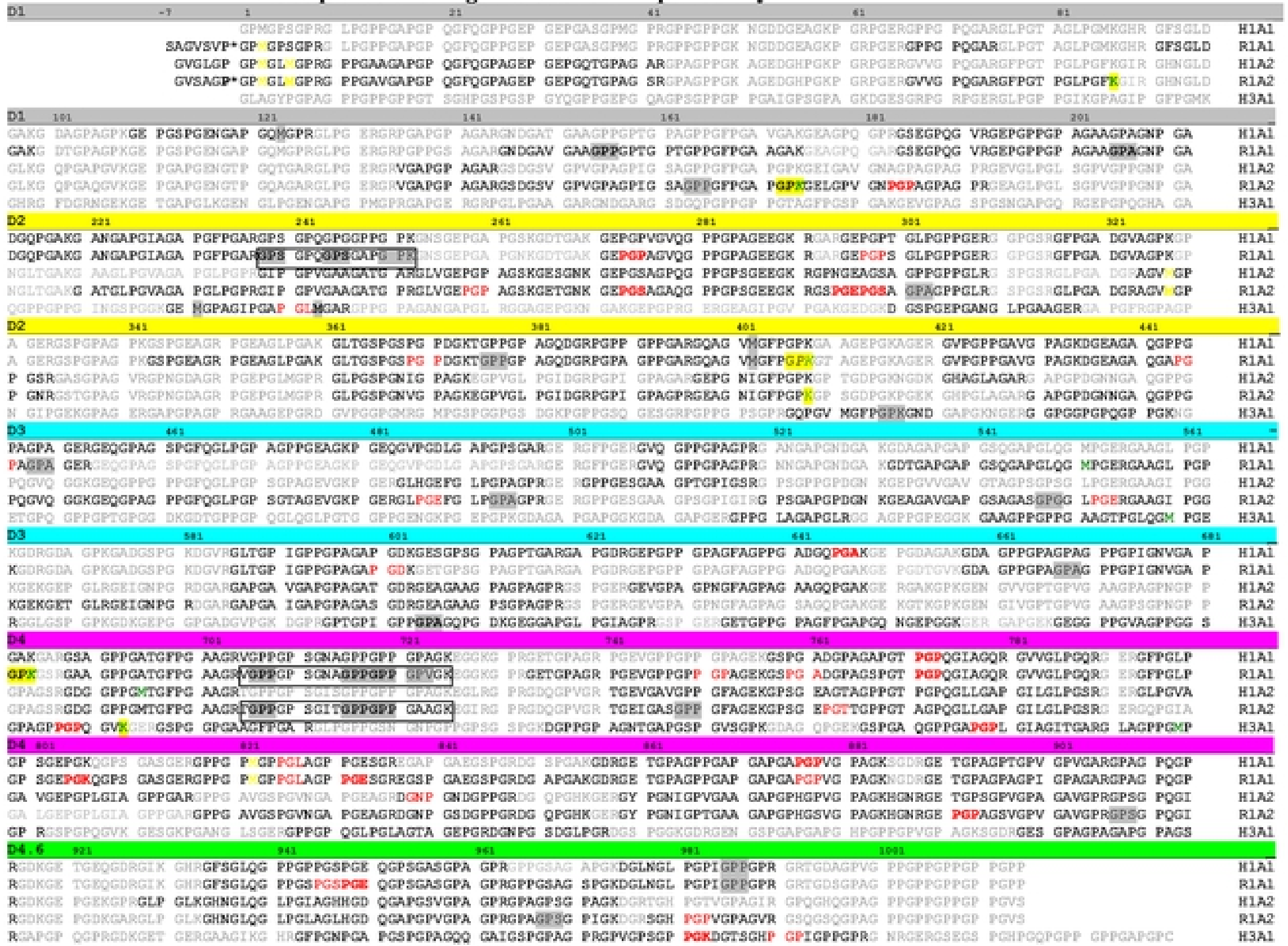

Figure 3 